\title{
Analysis of Regional Differences and Dynamic Mechanisms of Agricultural Carbon Emissions Efficiency in China's Seven Agricultural Regions
}

\author{
Xiaodan Zhang \\ Tongji University School of Economics and Management \\ Kaicheng Liao \\ Tongji University School of Economics and Management \\ Xianghong Zhou ( $\nabla$ xhztongji0927@163.com ) \\ Tongji University School of Economics and Management
}

\section{Research Article}

Keywords: dynamic efficiency, technological change, technological efficiency change, Dagum Gini coefficient, PVAR model

Posted Date: June 28th, 2021

DOl: https://doi.org/10.21203/rs.3.rs-545932/v1

License: (c) (1) This work is licensed under a Creative Commons Attribution 4.0 International License. Read Full License

Version of Record: A version of this preprint was published at Environmental Science and Pollution Research on January 25th, 2022. See the published version at https://doi.org/10.1007/s11356-02116661-w. 
4 Xiaodan Zhang1, Kaicheng Liao 1, Xianghong Zhou 1,2

51 School of Economics and Management, Tongji University, Shanghai, China, 200092;

6 Address: Building A, No.1 Zhangwu road, Yangpu district, Shanghai City, China.

72 corresponding author: Xianghong Zhou. E-mail: xhztongii0927@163.com Tel: +86 19121805801, Fax:

$8+8602165983383$.

Abstract:

11 A profound understanding of the present status and regional characteristics of China's agricultural carbon 12 emissions (ACE) is the basic prerequisite for exploring a pathway to ACE reduction that is compatible with China's national conditions. This study uses the inter-provincial agricultural industry panel data

14 from 2001 to 2017, and selects the three-stage slack-based measure data envelope analysis (SBM-DEA) 15 model and Malmquist Luenberger (ML) index model to measure the dynamic efficiency of agricultural 16 carbon emission (ACE). Additionally, this study uses the Dagum Gini coefficient and the panel vector 17 auto-regression (PVAR) model to analyze the sources of regional differences in dynamic efficiency and 18 the internal structure, respectively. The empirical results reveal the following: (i) The dynamic efficiency 19 of China's ACE is in a state of "efficiency optimization." Although both technological change and 20 technological efficiency change are in an "efficient" state, they also show a decline in technological 21 efficiency change, and a regression in technological change, respectively. (ii) The overall Dagum Gini coefficient of China's ACE dynamic efficiency, technological change, and technological efficiency

23 change all demonstrate upward trends. The gap between regions is the main reason for the long-term gap 24 between the dynamic efficiency of China's ACE, technological change, and technological efficiency 25 change. (iii) Regardless of the time horizon, technological change has always been the main driving force 26 for the continuous growth of dynamic efficiency; the contribution of technological change to dynamic 27 efficiency is far greater than that of technological efficiency change. This conclusion has been verified 28 in samples from different regions of China.

29 Keywords: dynamic efficiency; technological change; technological efficiency change; Dagum Gini coefficient; PVAR model

\section{Introduction}

33 As the global climate problem has become increasingly serious, the "low-carbon economy" has become 
a new schema for global development. According to the IPCC (2018) report, Global warming is $1.5^{\circ} \mathrm{C}$ higher than pre-industrial levels. Moreover, Agriculture's share of greenhouse gases cannot be underestimated, approximately $1 / 4$ of the total net artificial greenhouse gas emissions (GHG) and 14\% of the total global carbon emissions are related to agricultural activities (IPCC 2007) ${ }^{1,2}$. However, due to the widespread and universal nature of agricultural activities suggest that carbon emissions from this sector are an important source of global carbon emissions that must be addressed. (Fei and Lin 2016 and Dogan and Sebri et al. 2016). China's agricultural sector accounts for approximately $17 \%$ of the country's total carbon emissions (Dong et al.2008). Reducing carbon emissions and improving unit carbon emission efficiency are important measures for achieving low-carbon economic development (Beinhocker et al. 2008). Due to the increasing severity of the global climate problem, achieving emission reductions and low-carbon economic development have become matters of concern.

Many studies on ACE have been conducted. Early literatures focused on the factors that influence ACE. For instance, West et al. (2002) conducted an in-depth examination of the factors that influence ACE. In contrast, research by Johnson et al. (2007) found that ACE are primarily derived from livestock and poultry gas emissions, manure management, rice cultivation, arbitrary disposal of agricultural waste, and biological combustion. More recently, He and Dai (2016) highlighted that both the agricultural economic structure and the level of agricultural mechanization are leading factors that lead to differences in the spatial structure of agricultural carbon emissions in China. Moreover, Tian and Zhang (2017) found that chemical fertilizers, agricultural lime, pesticides, agricultural irrigation, and seed cultivation were the main sources of ACE.

Decomposition analysis of China's ACE is another area of burgeoning inquiry. Li and Li (2010) measured the amount of carbon dioxide emissions from energy consumption in China's agricultural sector from 1981 to 2007. Furthermore, Han and Zhang (2013) found that the import effect contributes at the greatest rate to China's current carbon emissions related to agricultural energy consumption, and followed by the export counter-effect, industrial scale effect, and energy efficiency effect. On this basis, they used the logarithmic mean Divisia index (LMDI) model to decompose carbon emissions, they found that economic growth was the most important driving factor for ACE. The comprehensive measurement of ACE has been used for calculating GHG emissions from energy crop cultivation based on carbon footprint (CFP) approaches. For example, Valin et al. (2013) investigated the effects of crop yield and livestock feed efficiency scenarios on GHG emissions from agriculture and land use change in developing countries. Besides that, Peter et al. (2017), have analyzed the available calculators and approaches according to the goal and scope of the calculator, the methodology used to account for GHG emissions from energy crop cultivation, energy crop cultivation management practices, and the ability to

1 IPCC. Intergovernmental Panel on Climate Change. Switzerland: IPCC WGI Fourth Assessment Report, 2007.

2 IPCC.Climate change 2007: mitigation of climate change. Contribution of working group III to the fourth assessment report of the intergovernmental panel on climate change .Cambridge, United Kingdom: Cambridge University Press: 63-67. 
model crop rotation. In addition, Ismael et al. (2018) used annual data for the period 1970 to 2014 to examine the interaction between agricultural technology factors and the environment in terms of carbon emissions in Jordan. Recently, LMDI decomposition and decoupling analysis has been used by researchers such as Liu et al. (2019) to test the changing trends and regional differences in China's ACE.

As research on ACE continues to deepen, scholars have shifted from simple ACE calculations to more comprehensive research on total factor productivity that relies on input and output analysis. Among the representative studies, Guo et al. (2018) used the SBM-Undesirable model with undesirable outputs to evaluate the total agricultural carbon emissions and carbon emission efficiency of various provinces in western China, and they found that the total amount of ACE in western China is increasing, and that there are obvious spatial differences regarding carbon emissions. In addition, Wang (2020) used the undesired output super-efficiency SBM model to empirically test the agricultural efficiency level and its spatial pattern in Anhui Province, China. Moreover, Lei et al. (2020) empirically tested the non-linear relationship between agricultural technological change and ACE efficiency by constructing a panelthreshold model .

Collectively, the aforementioned studies provide a wealth of theoretical value for exploring the ACE reduction. However, as the understanding of China's agricultural development continues to deepen, research on carbon emissions must move beyond the static level of index calculation and regional difference feature analysis. It is necessary to explore the dynamic efficiency of ACE and the internal mechanism of its formation.

The findings from the existing research on ACE not only lay an important theoretical and methodological basis for this study, but also highlight the insufficiency of research on ACE efficiency. In the relevant research on the total factor carbon emission productivity, the parametric method (e.g. Färe et al., 2005; Marklund and Samakovlis, 2007) and the non-parametric method (e.g. Liu et al., 2011; Zhou and Nie, 2012; Xu and Luan, 2018) are mainly used to measure the carbon emission production efficiency. Among them, non-parametric models are widely used by scholars in the evaluation of total-factor carbon emission efficiency because they do not need to establish functional forms and prior conditions in advance (e.g.Song et al., 2012; Molinos-Senante et al., 2016) , and can effectively avoid the subjectivity of parameter weighting (e.g. Zhou et al., 2010; Dong et al., 2017). In previous studies on ACE efficiency, most of them adopted the traditional data envelope analysis (DEA) model or SBM-DEA model as their analytical approach. These approaches ignore the influence of the external environment and random interference to a certain extent, and only consider the decision-making unit (DMU). Therefore, the estimated result is quite different from the actual situation (e.g. Tone, 2001; Choi et al., 2012; GómezCalvet et al., 2014; Iftikhar et al., 2016; Chen et al., 2017; Wu et al., 2019). To compensate for this shortcoming, this study uses the framework of Fried et al. (2002) to propose a three-stage DEA model based on a combination of the traditional DEA model and the stochastic frontier analysis (SFA) method. In addition, to explore the dynamic changes of ACE efficiency, we refer to existing studies (e.g. Kortelainen, 2008; Wang et al., 2014), and adopt the DEA-Malmquist-Luenberger index method to analyze the dynamics of ACE efficiency. The decomposition analysis explores dynamic efficiency, technological efficiency change, and technological change, and uses PVARmodel to test the dynamic relationship of these three factors. 
In summary, this paper divides China's 30 provincial-level administrative units into seven major

108 agricultural emission regions, and uses the three-stage SBM-DEA model and the ML index method to measure the ACE efficiency from a dynamic perspective. In addition, the Dagum Gini coefficient and

110 the PVAR model are used to empirically test the ACE in 30 provinces and regions of China from 2001

111 to 2017. The marginal contributions of this paper are as follows: first, the correct division of the study

112 area according to the research question is an important prerequisite for exploring the road to carbon

113 emission reduction in China's agricultural sector. Unlike previous studies, this study conducts an

114 empirical analysis of the regional differences in the dynamic efficiency of ACE and its formation

115 mechanism according to the division of the seven major agricultural regions ${ }^{3}$. Second, in contrast to

116 existing studies on the static efficiency of ACE, this study uses the undesired output super-efficiency

117 three-stage SBM-DEA model and the ML index decomposition method to measure the dynamic

118 efficiency of ACE. Third, this study not only focuses on the regional differences and contribution sources

119 of the dynamic efficiency of ACE in various regions, but also expands the research perspective to

120 evaluate the internal structure of dynamic efficiency. The findings of this research can be used to diagnose

121 the regional differences in the dynamic efficiency of ACE and their mechanisms, and to provide reference

122 about ACE reduction for policy makers and planning of relevant government entities.

\section{2. Research design}

\section{$125 \quad 2.1$ Dagum Gini coefficient and its subgroup decomposition method}

126 With reference to existing research, the study area is divided into seven major agricultural regions:

127 Northeast China, Huanghuaihai Region, The middle and lower reaches of the Yellow River, South China,

128 Northwest and Areas along the Great Wall, Southwest and Qinghai-Tibet Region. Dagum (1997) )'s

129 methods empirically test the dynamic efficiency, technological efficiency change (EC) and technological

130 change (TC) of ACE, and the regional differences among those three factors in China's seven major

131 agricultural regions. Dagum defines Gini coefficient as:

$$
G=\sum_{i=1}^{K} \sum_{j=1}^{K} \sum_{h=1}^{n_{i}} \sum_{r=1}^{n_{j}}\left|y_{i h}-y_{j r}\right| / 2 n^{2} \mu
$$

133 In the formula (1), $G$ represents the total Gini coefficient, which measures the total difference of ACE 134 between all provinces. $K$ represents the number of regions, including seven major agricultural regions.

$135 y_{i h}$ and $y_{j r}$ represent the true levels of the dynamic efficiency of ACE of all provinces and cities, and

\footnotetext{
3 According to the "National Agricultural Sustainable Development Plan (2015-2030)", the country is divided into seven major regions, namely the Northeast Region (Heilongiiang, Jilin, Liaoning), Huanghuaihai Region (Beijing, Tianjin, Hebei, Henan, Shandong), and the Yangtze River Middle and lower reaches (Jiangxi, Zhejiang, Shanghai, Jiangsu, Anhui, Hubei, Hunan), South China (Fujian, Guangdong, Hainan), Northwest and areas along the Great Wall (Xinjiang, NingXia, Gansu, Shaanxi, Shanxi,Inner Mongolia), Southwest Region (Guangxi, Guizhou, Sichuan, Chongqing, Yunnan), Qinghai-Tibet area (Qinghai, Tibet).
} 
$i=1,2, \ldots, K ; j=1,2, \ldots, K . \mu$ is the average value of the dynamic efficiency of ACE of all provinces and

137 cities, $\mathrm{n}$ is the number of all provinces and cities, and $n_{i}$ and $n_{j}$ are the number of provinces and cities.

$138 G$ can be decomposed into three parts: intra-regional gap $G_{w}$, inter-regional gap $G_{r b}$, and tansvariation intensity $G_{t}$. The three parts satisfy: $G=G_{w}+G_{r b}+G_{t}$. Among them, $\mathrm{Gw}$ represents the distribution gap of the dynamic efficiency of ACE in the $i(j)$ region. Grb represents the distribution gap of the dynamic efficiency of agricultural carbon emissions between regions $i(j)$. $G_{t}$ represents the impact of the cross term of the dynamic efficiency of ACE between regions on the total Gini coefficient $G$. If $G_{t}=0$, it means that the cross term of the dynamic efficiency of ACE between regions does not exist. The specific decomposition formula is as follows:

$$
G_{w}=\sum_{i=1}^{K} \lambda_{i} s_{i} G_{i i}
$$

146 Fromula (2) measures the contribution of the difference of dynamic efficiency of ACE within region to 147 the total Gini coefficient G;

$$
G_{r b}=\sum_{i=2}^{K} \sum_{j=1}^{i-1}\left(\lambda_{j} s_{i}+\lambda_{i} s_{j}\right) G_{i j} D_{i j}
$$

Formula (3) measures the net contribution of the extended difference of dynamic efficiency of ACE between regions to the total Gini coefficient $G$;

$$
G_{t}=\sum_{i=2}^{K} \sum_{j=1}^{i=1}\left(\lambda_{j} s_{i}+\lambda_{i} s_{j}\right) G_{i j}\left(1-D_{i j}\right)
$$

Formula (4) measures the contribution of the transvariation intensity between regions to the total Gini coefficient $G . \lambda_{i}=n_{i} / n$ and $s_{i}=\lambda_{i} \mu_{i} / \mu, \mu_{i}$ and $\mu_{j}$ are the average of dynamic efficiency of ACE.

154 In Eq. (10), $D_{i j}=\left(d_{i j}-p_{i j}\right) /\left(d_{i j}+p_{i j}\right)$ is the relative economic affluence between the $i t h$ and the $j t h$ region, and the gross economic affluence $d_{i j}$ between the $i t h$ and the $j$ th region, such as $\mu_{i}>\mu_{j}$, is

157 Where $d_{i j}$ is under the condition of $y_{i h}>y_{i r}$, the weighted average of the dynamic efficiency gap $\left(y_{i h}-y_{i r}\right)$ of 158 all ACE under the following conditions. For the continuous density distribution functions $f_{i}(y)$ and $f_{j}(y)$. $p_{i j}$ is the first-order moment of transvariation intensity between the $i$ th and the $j t h$ region, such that $\mu_{i}>\mu_{j}$ is

$$
d_{i j}=\int_{0}^{\infty} \int_{0}^{y}(y-x) f_{j}(x) d x f_{j}(y) d y
$$




$$
G_{i j}=\sum_{h=1}^{n_{i}} \sum_{r=1}^{n_{j}}\left|y_{i h}-y_{j r}\right| / n_{i} n_{j}\left(\mu_{i}+\mu_{j}\right)
$$

\subsection{The Super-efficiency three-stage SBM-ML model of undesired output}

The super-efficiency three-stage SBM-ML model of undesired output can be used to analyze the dynamic changes of carbon emission efficiency. The three-stage process is: the first stage uses the undesired output super-efficiency SBM-DEA model to analyze the changes in total factor productivity; the second stage uses the stochastic frontier method to adjust the input-output variables; the third stage will adjust the Input variables and original output variables are substituted into the undesired output super-efficiency SBM-ML model for measurement.

(1) The first stage: use the super-efficiency SBM-DEA model of undesired output to calculate the initial efficiency of each decision-making unit (DMU) and the slack variables of input-output. The SBM-DEA model is:

$$
\rho=\min \frac{1-\frac{1}{m} \sum_{i=1}^{m} \frac{s_{i}^{-}}{x_{i 0}}}{1+\frac{1}{s_{1}+s_{2}}\left(\sum_{r=1}^{s_{1}} \frac{s_{r}^{g}}{y_{r 0}^{g}}+\sum_{r=1}^{s_{2}} \frac{s_{r}^{b}}{y_{r 0}^{b}}\right)}
$$

$$
\text { subject to }\left\{\begin{array}{l}
x_{0}=X \lambda+S^{-} \\
y_{0}^{g}=Y^{g} \lambda-S^{g} \\
y_{0}^{b}=Y^{b} \lambda+S^{b} \\
S^{-} \geq 0, S^{g} \geq 0, S^{b} \geq 0, \lambda \geq 0
\end{array}\right.
$$

177 Where $\lambda$ is the weight vector. $x$ and $y$ are matrixes that compose of the input and output of all DMU, which $y^{g}$ is the expected output, $y^{b}$ is the undesired output. $m$ are the number of input indicators, $S$ are the number of outputs indicators ( $S_{1}$ represents expected output, $S_{2}$ represents undesired output). $n$ is the number of DMU. $S 、 S^{g} 、 S^{b}$ are the slack variables of input variables, expected output and undesired output, respectively. $\rho$ is the carbon emission efficiency value, and $0 \leq \rho \leq 1$. When $\rho=1, S^{s}=S^{g}=S^{b}=0$. At this time, it is completely efficient for this particular DMU; when $\rho<1$, it means that the DMU is inefficient, and the input variables and output variables need to be improved to improve efficiency.

184 From observing formula, it can be found that input-output slack variables are directly substituted into the objective function for calculation. On the one hand, it solves the problem of slackness of input and output variables in the traditional DEA model, and on the other hand, it also effectively solve the problem of expected and undesired output in output variables. Therefore, the SBM model is more effective in evaluating carbon emission efficiency issues. 
(2) The second stage: First, construct and use the stochastic frontier analysis (SFA) to decompose the input relaxation value obtained in the first order stage. The SFA regression model is:

$$
S_{i j}=f\left(Z_{j} ; \beta_{i}\right)+v_{i j}+\mu_{i j} \quad(i=1,2, \mathrm{~K}, I ; j=1,2, \mathrm{~K}, J)
$$

Where $S_{i j}$ is the slack variable of the $i t h$ input of the $j t h$ DMU, $Z_{j}$ is the environmental variable, $\beta_{i}$ is the coefficient of the environmental variable, $v_{i j}+\mu_{i j}$ represents the mixed error term, $v_{i j}$ is random error, and $\mu_{i j}$ is the managerial inefficiency, which means the influence of managerial factors on the input slack variable, assumed it follows the truncated half-normal distribution at the zero point, ie. $\mu \sim N^{+}\left(0, \sigma_{\mu}^{2}\right)$

Using the SFA model, the input slack variables of the 30 provincial regions from 2001 to 2017 obtained in the first stage were used as the explanatory variables, economic development level, industrial structure, energy structure, government regulation, technological innovation level and degree of opening to the outside world which six environmental factors were used as explanatory variables for regression analysis. Frontier4.1 was used to obtain SFA regression results. In order to make the calculation results more precise, this paper adopts the method of year-by-year analysis and establishes a total of 54 regression equations.

The input-output slack variable calculated in the first stage is affected by managerial inefficiency, environmental factors and statistical noise. Therefore, it is necessary to isolate these three effects and eliminate environmental factors and random errors. The specific separation method is as follows: Separate environmental factors, managerial inefficiency, and random errors:

$$
E(\mu / \varepsilon)=\sigma_{*}\left[\frac{f\left(\lambda \frac{\varepsilon}{\sigma}\right)}{\varphi\left(\lambda \frac{\varepsilon}{\sigma}\right)}+\frac{\lambda \varepsilon}{\sigma}\right]
$$

Where: $\sigma_{*}=\frac{\sigma_{\mu} \sigma_{v}}{\sigma}, \sigma_{*}=\sqrt{\sigma_{\mu}^{2}+\sigma_{v}^{2}}, \lambda=\sigma_{\mu} / \sigma_{v}, \varepsilon=\mu_{i j}+v_{i j}$ In this way, the random error term can be separated from the mixed error term, and the separation equation is:

$$
E\left[v_{i j} /\left(v_{i j}+u_{i j}\right)\right]=S_{i j}-f\left(Z_{j} ; \beta_{i}\right)-E\left[u_{i j} /\left(v_{i j}+u_{i j}\right)\right]
$$

211 Finally, adjust the input and output variables. Separating managerial inefficiency, environmental factors and random errors in slack variables in order to put all DMU in the same external environment for efficiency evaluation, so there are two adjustment methods. One is to adjust all DMU to a superior external environment, which can be adjusted by reducing the input and output of other DMU; the other is to adjust to a in-superior external environment and increase the input and output of other DMU. This paper chooses the second adjustment method in view of the operability of the data, and its equation is: 


$$
X_{i j}^{A}=X_{i j}+\left\{\max \left[f\left(Z_{j} ; \beta_{i}\right)\right]-f\left(Z_{j} ; \beta_{i}\right)\right\}+\left[\max \left(v_{i j}\right)-v_{i j}\right]
$$

218 Above formula represent adjusted input variable and $X_{i j}$ represent before adjusted input variable. In 219 summary, all DMU will be placed in the same external environment.

220 (3) The third stage: The adjusted input value removes the external environment factors and random interference factors, then recalculate it with the initial output data using the undesired output superefficiency SBM-ML model. The efficiency value at this time eliminated the influence of environmental factors and random errors, and can more accurately reflect the true efficiency of the internal management

224 and investment scale of each DMU.

The undesired output super-efficiency SBM model can only be used to analyze the static environmental efficiency of regions, but it cannot effectively measure the dynamic environmental efficiency of regions. Färe et al. (1992) proposed the calculation method of Malmquist index which can be used to analyze the efficiency of dynamic environment. Chung et al. (1997) introduced the directional distance function into the Malmquist index to deal with the problem of undesired output, and called it The ML index, which has all the virtues of the Malmquist index model. On this basis, not only the undesired output is taken into account, but also the decrease of undesired output and the increase of expected output are taken into consideration simultaneously. Therefore, this paper adopts the super-efficiency SBM-ML index, which includes undesired output, to measure the dynamic total factor carbon emission efficiency of 30 provincial regions from 2001 to 2017. According to the ML index calculation method proposed by Chung et al. (1997), it is assumed that the "bad" output is weakly disposed and the "good" output is freely disposed. The direction vector $g^{t}=\left(y^{t},-b^{t}\right)$, then the ML productivity index from $t$ period to $t+1$ is:

$$
M L_{t}^{t+1}=\sqrt{\frac{\left[1+D_{0}^{t}\left(x^{t}, y^{t}, b^{t} ; y^{t},-b^{t}\right)\right]}{\left[1+D_{0}^{t}\left(x^{t+1}, y^{t+1}, b^{t+1} ; y^{t+1},-b^{t+1}\right)\right]} \bullet \frac{\left[1+D_{0}^{t+1}\left(x^{t}, y^{t}, b^{t} ; y^{t},-b^{t}\right)\right]}{\left[1+D_{0}^{t+1}\left(x^{t+1}, y^{t+1}, b^{t+1} ; y^{t+1},-b^{t+1}\right)\right]}}
$$

239 ML measures the change in productivity from period $t$ to period $t+1$. If $M L<1$, production efficiency decline, when $M L=1$, production efficiency remains unchanged, and if $M L>1$, production efficiency 241 ascending. The ML index can be further decomposed into two parts: one part measures technological 242 efficiency change (EC), and the other part measures technological change (TC). The expression is as 243 follows:

$$
M L_{t}^{t+1}=M L E F F C H_{t}^{t+1} \bullet M L T E C H_{t}^{t+1}
$$

$$
\operatorname{MLEFFCH}_{t}^{t+1}=\frac{1+\mathrm{Du}_{0}^{t}\left(x^{t}, y^{t}, b^{t} ; y^{t},-b^{t}\right)}{1+D_{0}^{t+1}\left(x^{t+1}, y^{t+1}, b^{t+1} ; y^{t+1},-b^{t+1}\right)}
$$


$\operatorname{MLTECH}_{t}^{t+1}=\sqrt{\frac{\left[1+D_{0}^{t+1}\left(x^{t}, y^{t}, b^{t} ; y^{t},-b^{t}\right)\right]}{\left[1+D_{0}^{t}\left(x^{t}, y^{t}, b^{t} ; y^{t},-b^{t}\right)\right]} \bullet \frac{\left[1+D_{0}^{t+1}\left(x^{t+1}, y^{t+1}, b^{t+1} ; y^{t+1},-b^{t+1}\right)\right]}{\left[1+D_{0}^{t}\left(x^{t+1}, y^{t+1}, b^{t+1} ; y^{t+1},-b^{t+1}\right)\right]}}$

$247 E C$ measures how close each observation value is to its respective production frontier, while $T C$ measures

248 the change in the production possibility boundary from period $t$ to period $t+1$. Among them, when $E C>1$

249 means that the technological efficiency is improved; EC $<1$ means that the technological efficiency is

250 reduced. $T C>1$, indicating technological improved; TC $<1$, indicating technological regression. $M L>1$,

251 indicating that the efficiency has increased; $M L<1$, indicating that the efficiency has decreased.

\section{3. Data and variable selection}

253 Based on the panel data of 30 provinces, municipalities, and autonomous regions in China from 2001 to

$2542017^{4}$. According to the classification standard of "National Economic Industry Classification" ${ }^{5}$, this

255 paper focuses on the dynamic efficiency of ACE and uses undesired output. The super-efficiency three-

256 stage SBM-ML model. The required data mainly comes from the 2001-2017 China Statistical Yearbook,

257 China Energy Statistical Yearbook, China Science and Technology Statistical Yearbook, local statistical

258 yearbooks and bulletins. Part of the missing data is supplemented by research methods such as

259 interpolation, exponential smoothing, and mean method. In order to test the interval difference in the

260 dynamic efficiency of agricultural carbon emissions, the study divided the regions according to the seven

261 major agricultural region, and conducted empirical analysis on samples from different regions. The

262 specific variables are selected as follows:

263 (1) Selection of input-output variables. From the research of $\mathrm{Li}$ et al. (2020), this paper takes labor,

264 capital stock, and total energy consumption as input variables, and regional agricultural production and

265 carbon dioxide emissions as output variables. The specific description of the variables is shown in Table 2661.

267 (2) Selection of environment variables. For the selection of environmental variables in the three-stage

268 DEA model, the main criterion is that the selection has a significant impact on the efficiency of carbon

269 dioxide emissions, but it is also a factor that cannot be controlled by the DMU. Based on comprehensive

270 consideration of data availability, representativeness of variable indicators and existing research (e.g.

271 Chen et al., 2017; Huang and Bai, 2019), this study focuses on economic energy, institutional

272 environment, and six indicators are selected as the environmental variables in this paper. They are

273 economic development level, industrial structure, energy structure, government regulation, technological

4 There are 34 provinces in China. For the reason of the lack of data, Tibet, Macau, Hong Kong and Taiwan are excluded from the sample.

5 The "Classification of National Economic Industries" (GB/T4754-2003) divides my country into 3 major industries and 6 major industries. Among them, the three major industries include the primary, secondary and tertiary industries; and the six major industries cover agriculture, forestry, animal husbandry, and fishery; Agriculture; construction industry; transportation, storage, post and telecommunications industry; wholesale, retail and accommodation, catering industry; other industries. 
274 innovation level, and degree of openness to the outside world. The level of economic development. This

275 paper uses regional GDP per capita to express the level of regional economic development.

Table 1 Indicators for Measuring and Calculating the China's ACE efficiency

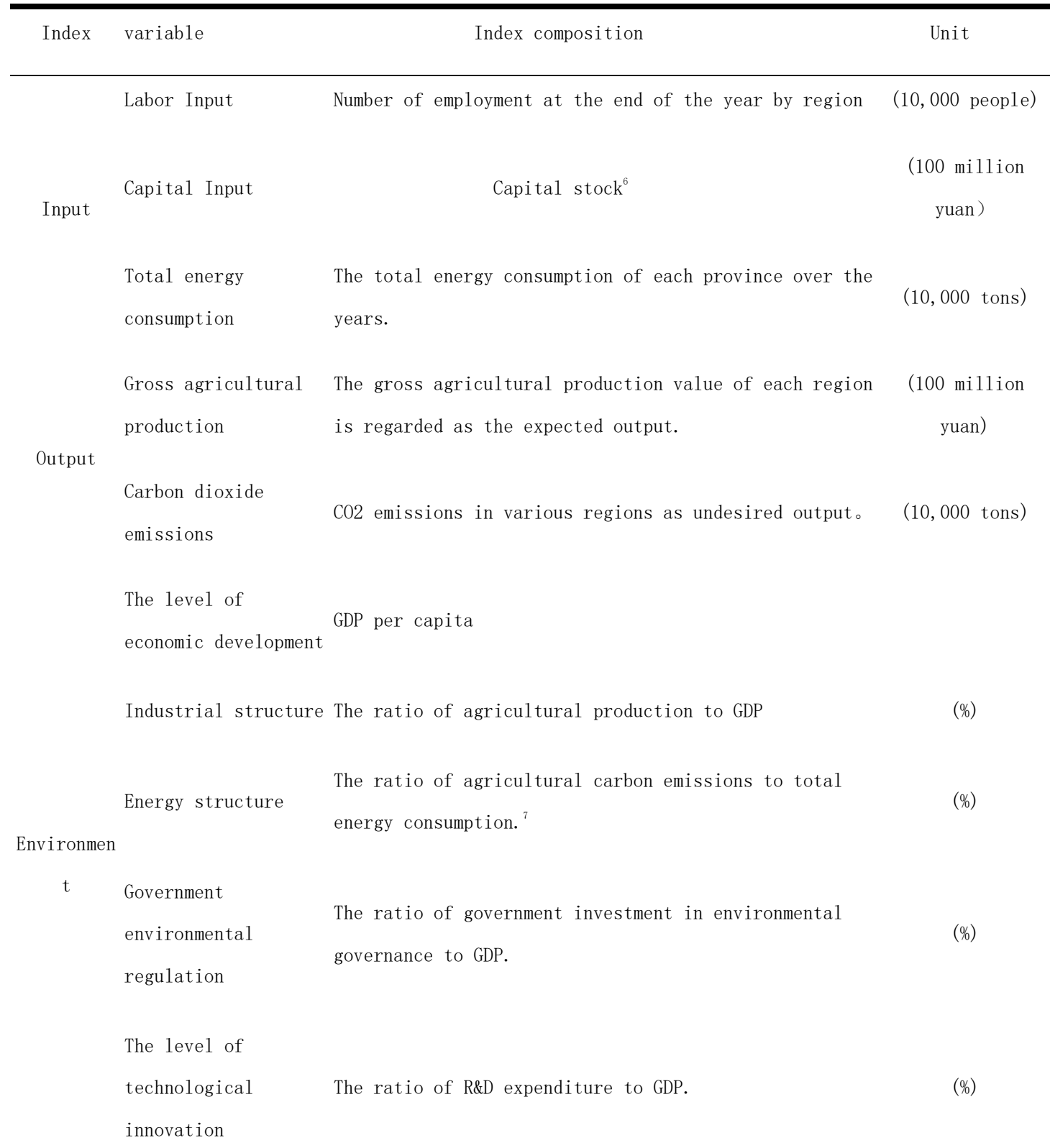

6 Calculation method: First, based on the construction method of Zhang (2004) and Shan (2008) about capital stock, the price deflator of the investment data of various industries in this article is calculated by Xu (2007)'s deflation index construction method. Then, Drawing on the provincial depreciation rate and base period capital stock data calculated by Zong (2014) method, according to the perpetual inventory method, the provincial capital stock data of the three industries in this paper are obtained. Finally, through the calculation of the amount of capital in the base period and the selection of depreciation rates and current investment indicators, the total investment in fixed assets of the whole society is then deflated.

7 Calculation method: According to the calculation formula in the "Guidelines for National Greenhouse Gas Inventories" compiled by the United Nations Intergovernmental Panel on Climate Change in 2006 (IPCC, 2006) 


\section{Decomposition of regional differences in agricultural carbon emission efficiency in China}

\subsection{Overview of china's ACE efficiency}

281 Figures 1-3 show the temporal and spatial evolution of the ACE dynamic efficiency (ML), EC, and TC in China from 2001 to 2017, respectively.

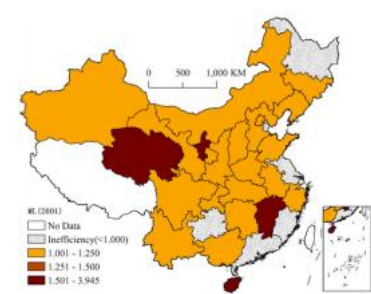

(1) 2001

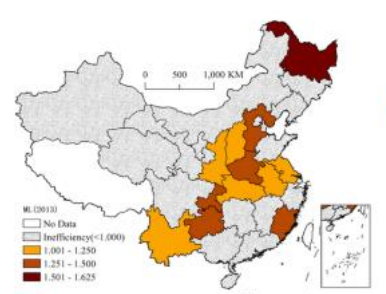

(4) 2013

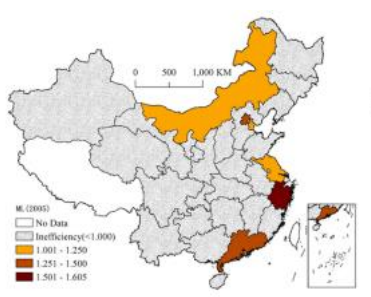

(2) 2005

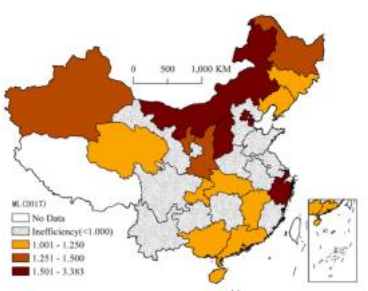

(5) 2017

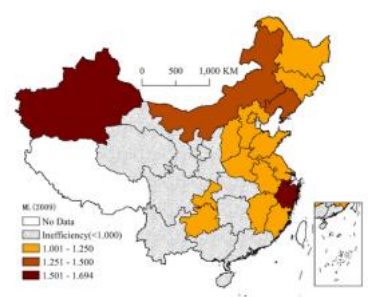

(3) 2009

Fig. 1 Distribution of the dynamic efficiency of China's ACE efficiency

In Figure 1, in 2001, ML exhibited a spatially distributed orderly pattern, with higher values in western regions and lower in eastern regions, and an overall average efficiency of 1.199. Among the 30 regions, 23 regions had ML $>1$ (efficiency growth areas) and 7 regions had ML $<1$ (efficiency decline areas), most of which were agglomerated in the middle and lower reaches of the Yangtze River and the Huanghuaihai region. By 2005, ML was distributed in a point-like space, and the overall average efficiency decreased to 0.885 , whereas the efficiency growth area was mainly clustered in economically developed areas. By 2009, the spatial distribution of ML showed higher values in eastern and northern regions and lower values in western and southern regions, and the overall average efficiency increased to 1.034. Efficiency decline areas reduced, with 13 regions in total, whereas efficiency growth areas were mainly distributed in the Northeast, Huanghuaihai region, and the middle and lower reaches of the Yangtze River. By 2013, the overall average efficiency decreased to 0.994; the number of efficiency decline regions increased, and the efficiency growth areas were mainly located in the middle and lower reaches of the Yangtze River. By 2017, the overall average efficiency increased to 1.321; efficiency growth regions also further increased, the distribution was more dispersed, and the efficiency of economically developed regions and agricultural-based regions was higher. 


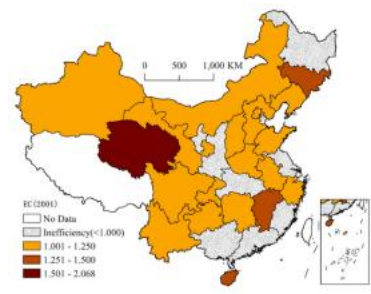

(1) 2001

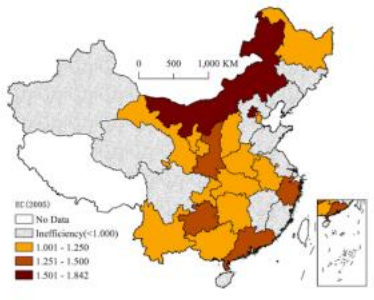

(2) 2005

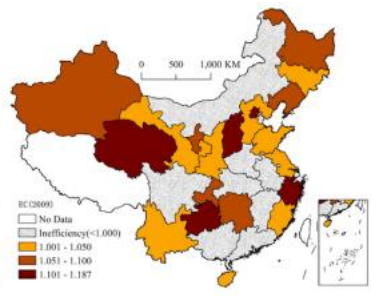

(3) 2009

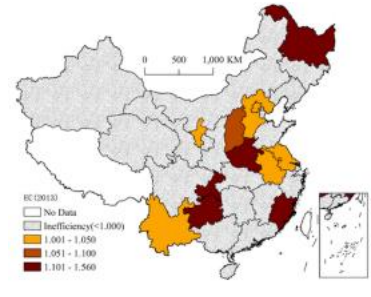

(4) 2013

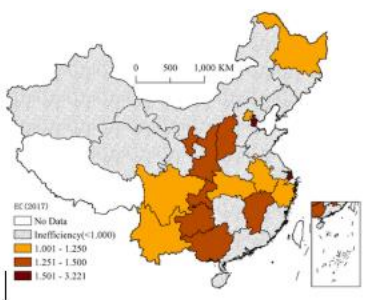

(5) 2017

Fig. 2 Distribution of the technological efficiency change of China's ACE efficiency

304 In Figure 2, in 2001, the overall average EC was 1.065; from the total area, two-thirds were EC growth 305 areas $(E C>1)$, and one-third were efficiency decline areas $(E C<1)$. In 2005, the overall average EC was 306 1.124, whose spatial distribution showed higher values in central regions and lower values in eastern and 307 western regions. The number of EC decline regions did not considerably change. However, the overall 308 EC of the Northwest and Southwest regions declined. By 2009, EC showed a horizontal band distribution, 309 with an overall average efficiency of 1.013. The areas of EC growth were mainly concentrated along the 310 Yellow River Belt, Northeast China, and Southwest China. The EC decline areas decreased to one-third, 311 and were mainly concentrated in the middle and lower reaches of the Yangtze River and the southern 312 coastal regions. By 2013, EC was distributed in a small-scale block-like spatial structure, with an overall 313 average efficiency of 0.946 ; technology decline areas further expanded, mainly distributed in the

314 Northwest and areas along the Great Wall, middle and lower reaches of the Yangtze River, Northeast 315 China, South China, and Southwest China. By 2017, the overall average EC was 1.146, the number of 316 decline areas of EC reduced, and the spatial distribution of increasing efficiency areas moved to the 317 Southwest. 


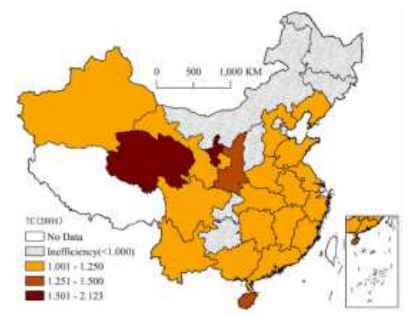

(1) 2001

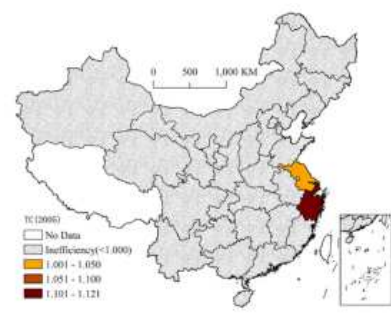

(2) 2005

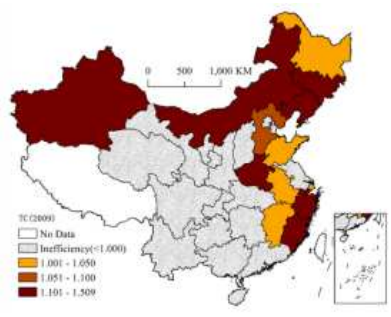

(3) 2009

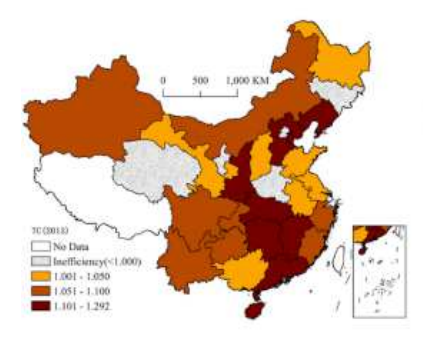

(4) 2013

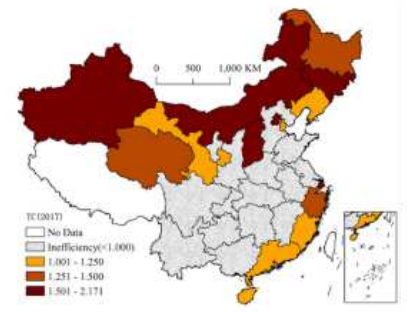

(5) 2017

Fig. 3 Distribution of the technological change of China's ACE efficiency

321 It can be seen from Figure 3 that in 2001, TC in most of the China regions showed a growing tendency,

322 being evenly distributed in the eastern and western regions. The declining areas of TC were distributed in a dot-like pattern, and regions of inefficiency of TC in parts of the middle and lower reaches of the

324 Yangtze River and the southwestern region expanded. By 2005, Only three regions remained with TC>1, all of which were agglomerated in the middle and lower reaches of the Yangtze River. By 2009, the number of regions with TC growth gradually expanded, mainly in the Northeast and Huanghuaihai regions. Until 2013, the TC growth type areas showed an orderly pattern of high TC in the middle and low TC in the East. In South China, TC degraded from growth type to decline type. In 12 regions, concentrated in the Southwest, Huanghuaihai region, and the middle and lower reaches of the Yangtze River, TC upgraded from decline to growth. Finally, by 2017, the growth area of TC showed a flaky type distribution pattern in the North and South.

\section{4.2 Decomposition of regional differences of China's ACE efficiency}

334 The dynamic tendencies of the sources of regional differences in China's ACE are illustrated in Figure 3354. 


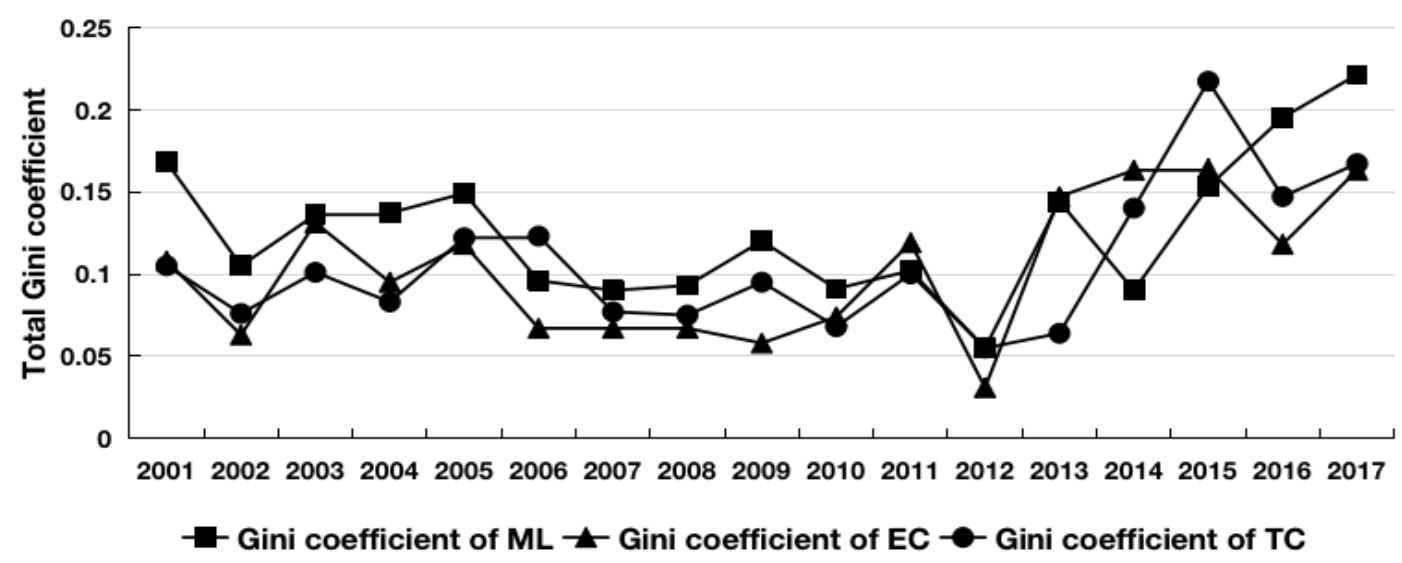

Fig. 4 The total Gini coefficient of the China's ACE dynamic efficiency, technological efficiency change, and technological change

By analyzing the Gini coefficient of ML (GML), from 2001 to 2017, GML showed an upward tendency of volatility, with an average annual growth rate of $1.729 \%$, which indicates that the gap of ML across China was gradually expanding, and the Gini coefficient of EC (GEC) and TC (GTC) also showed an upward tendency, with average annual growth rates of $2.606 \%$ and $2.943 \%$, respectively. In terms of inter-annual changes, GML, GEC, and GTC showed W-shaped fluctuations. It can be observed that the changes in GML were mainly due to the effects of GEC and GTC. However, in different periods, considerable differences were observed between the two contributions to GML fluctuations.

346 Figure 5a-5c presents the differences in China's ACE dynamic efficiency, technological efficiency change, and technological change among the regions from 2001 to 2017, respectively. It can be seen that the GML changes in various regions were considerably different. Among them, the GML in Northeast and South China showed a downward tendency, and South China had the maximum decrease (6.993\%). Furthermore, the GML in the other regions showed an upward tendency. The GML in the Huanghuaihai region exhibited the largest increase (10.582\%). The GEC of South China and Southwest China showed a downward tendency from 2001 to 2017. In addition, South China had the largest decline (7.207\%),

353 GEC in other regions showed an upward tendency, and the overall gap gradually widened. For the GTC, 354 from 2001 to 2017, it showed a downward tendency in the Northeast, South China, Northwest, and areas along the Great Wall, whereas in the remainder regions, an overall upward tendency was observed, with the largest increase (11.973\%) in the Huanghuaihai region. 


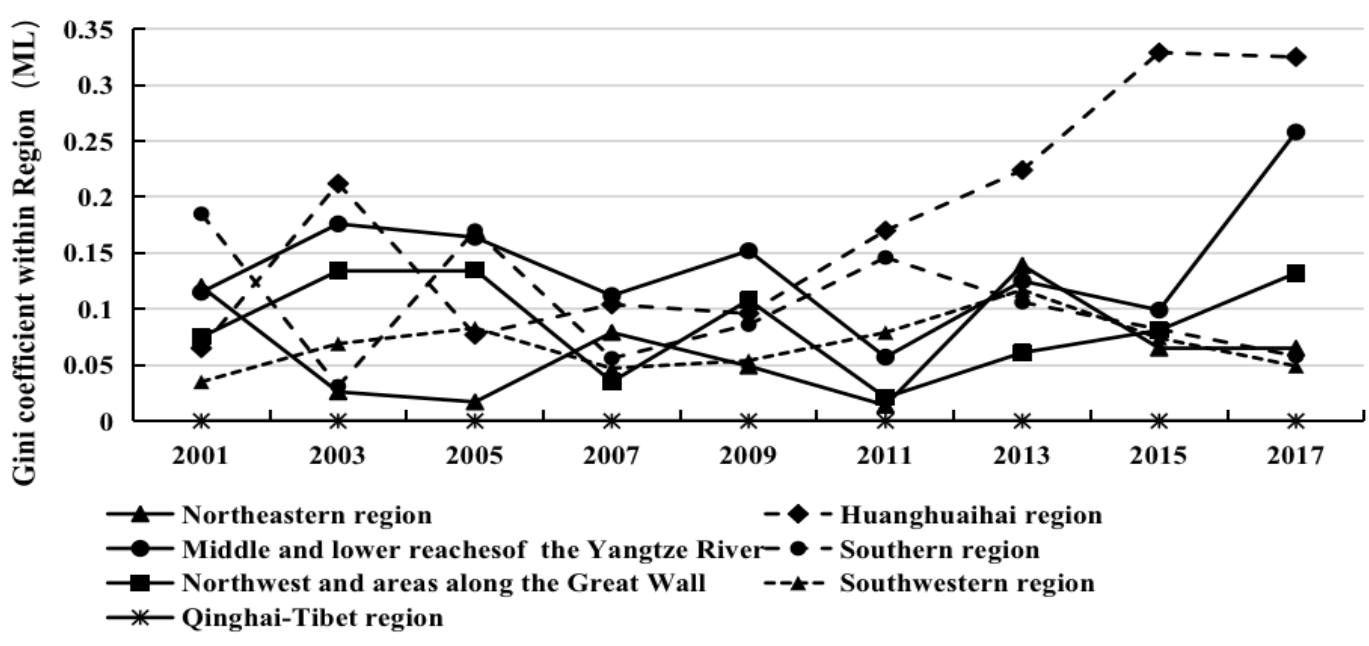

Fig. 5a Tendency of differences in China' s ACE dynamic efficiency

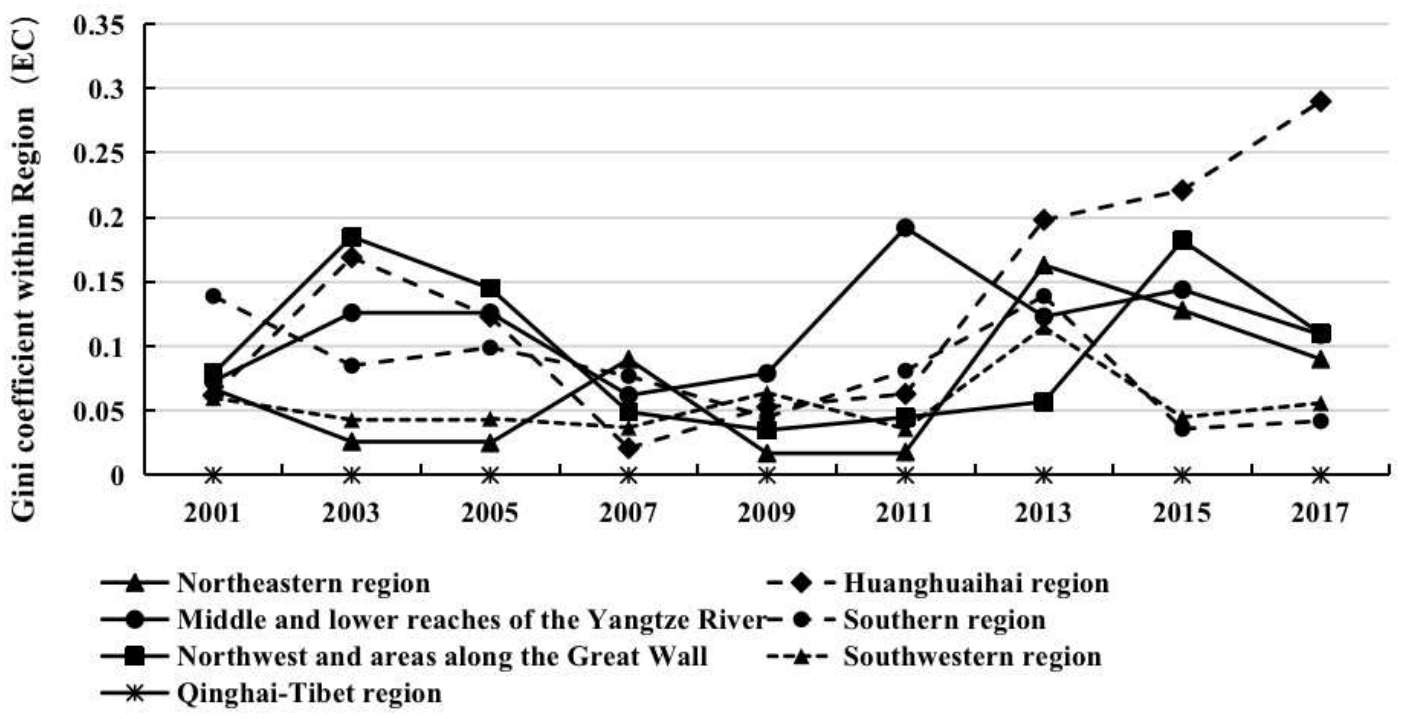

361 Fig. 5b Tendency of differences in China' s ACE technological efficiency change

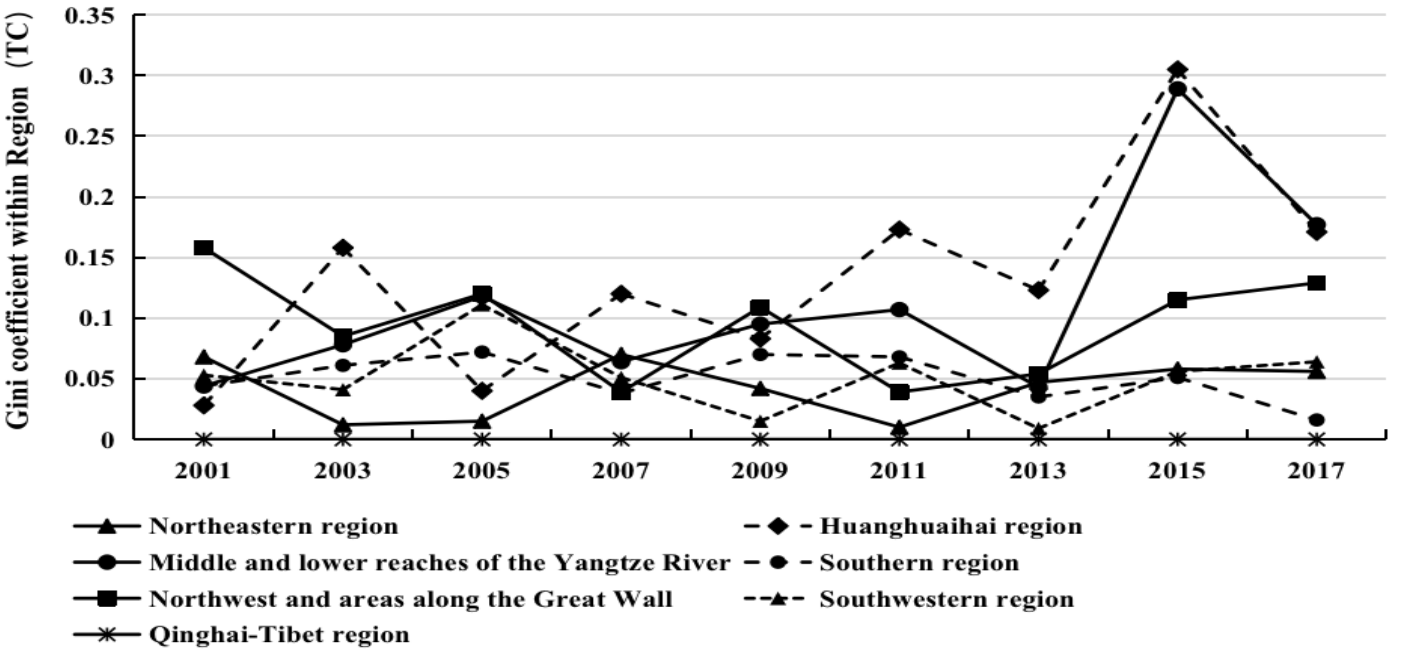

Fig. 5c Tendency of differences in China' s ACE technological change 
364 Note: Since there is only Qinghai in Qinghai-Tibet area, the intra-group difference is 0.

365

366

Table 2 Results of inter-group differences

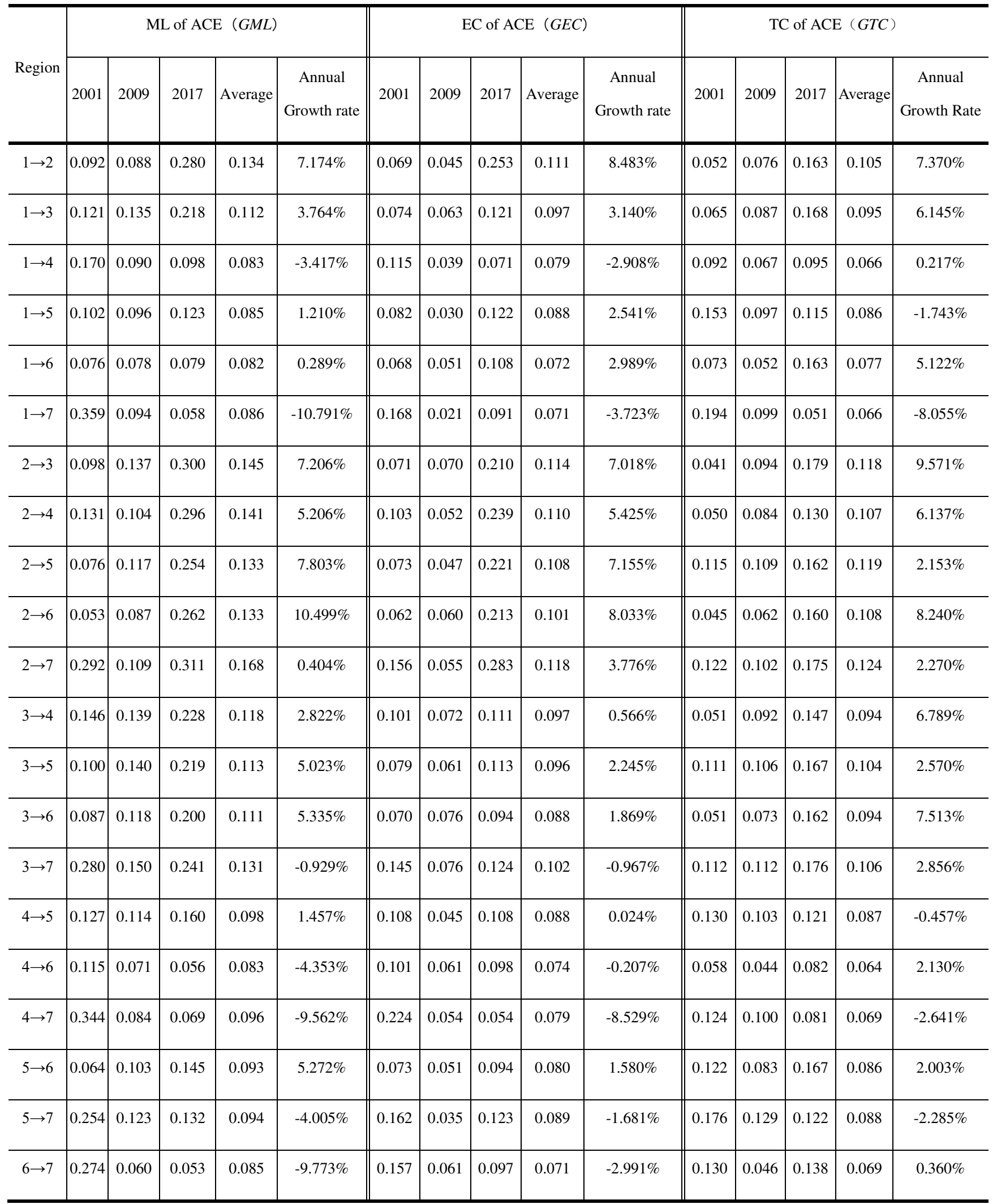




\begin{tabular}{l|l|l|l|l|l||l|l|l|l|l||l|l|l|l|l} 
Average & 0.160 & 0.107 & 0.180 & 0.111 & $0.983 \%$ & 0.108 & 0.054 & 0.140 & 0.092 & $1.611 \%$ & 0.099 & 0.086 & 0.139 & 0.092 & $2.679 \%$ \\
\hline
\end{tabular}

367 Note: 1, 2, 3, 4, 5, 6, and 7 in the table correspond to the Northeast, Huanghuaihai, Middle and Lower Yangtze River,

368 South China, Northwest and areas along the Great Wall, Southwest, and Qinghai-Tibet region, respectively.

369 From table 2, it can be seen that during the research period, the inter-region differences of GML, GEC, and GTC were at different levels, and the overall tendency of fluctuations was evident. The overall

371 average annual growth rate of the inter-region difference of GML ranged from $10.79 \%$ to $10.50 \%$.

372 Moreover, the inter-region difference of GML in most regions showed an upward tendency. Among them,

373 the largest increase occurred between Northeast China and the middle and lower reaches of the Yangtze

374 River, with a rate of $10.50 \%$, and the smallest increase occurred between the middle and lower reaches

375 of the Yangtze River and Southwest China $(0.40 \%)$. The largest decrease was between the Huanghuaihai

376 District and Southwest China, at 10.79\%, whereas the Northwest and the areas along the Great Wall and

377 Southwest Region had the smallest decline of $0.93 \%$.

378 In contrast to GML, the overall average annual growth rate of the inter-region difference of GEC ranged 379 from $8.529 \%$ to $8.483 \%$, and GEC also showed an upward tendency in most regions. Moreover, the 380 average annual increase between South China and the Northwest and the Great Wall was the smallest 381 (0.024\%), whereas the Northeast and Huanghuaihai regions had the largest average annual increase 382 (8.483\%). Moreover, South China and Southwest China had the largest average annual decrease 383 (8.529\%), whereas South China and Southwest China had the lowest average annual decrease $(0.207 \%)$.

384 Considering the GTC, the overall average annual growth rate of the inter-region difference ranged from $3858.055 \%$ to $9.571 \%$. Similarly, most regions showed an upward tendency. The Huanghuaihai region and 386 the middle and lower reaches of the Yangtze River had the largest average annual increase $(9.571 \%)$, whereas the Northeast and South China had the smallest average annual increase $(0.217 \%)$. Furthermore,

388 the Northeast and Qinghai-Tibet regions had the largest average annual decrease (8.055\%), whereas 389 South China, Northwest, and along the Great Wall had the smallest average annual decrease $(-0.457 \%)$.

4.3 Research on the source decomposition and contribution rate of regional differences of China's ACE efficiency

392 Figure 6a-6c exhibit sources of differences between ML, EC, and TC and their contribution rate from 3932001 to 2017 , respectively.

394 Considering GML, the contribution to the gap of GML in various parts of China were 46.743\%, 39.419\%, and $13.840 \%$, for Grb (the inter-region gap), Gt (transvariation intensity), and Gw (the intra-region gap), respectively. Grb is the main responsible for the gap of GML in China. From the perspective of interannual changes, Grb and Gt have considerably different contributions to the gap of GML in different periods. Among the years analyzed, for 2003, 2007, 2009, 2012, 2013, 2015, and 2017, the contribution rates of Gt to GML were higher than those of Grb, ranging from $42.638 \%$ to $59.338 \%$. Gt is mainly used to describe the phenomenon of overlap between regions.

401 Similarly, in terms of GEC, we found that $\mathrm{Grb}, \mathrm{Gt}$, and $\mathrm{Gw}$, respectively, provided the major contributions 402 to the gap of GML in various parts of China, and Grb contributed the most to the gap of GEC 

2015, the contribution rate of Gt was ranked first, ranging from $43.384 \%$ to $58.049 \%$. The contribution rate of Gw to GEC fluctuated between $11.297 \%$ and $16.398 \%$, with an average annual growth rate of $1.125 \%$.

For GTC, the major contribution to the gap of GTC in various parts of China was still due to Grb, followed by Gt and Gw. From the perspective of inter-annual changes, Grb and Gt alternately became the main contributors for the regional gap of GTC. Moreover, in the two stages of 2007-2008 and 20112014, the contribution rates of Gt to GTC were higher than those of Grb. Therefore, Gt was the main responsible for the regional gap of GTC. In contrast, the contribution rate of Gw was stable from 11.808\%

412 to $16.113 \%$.
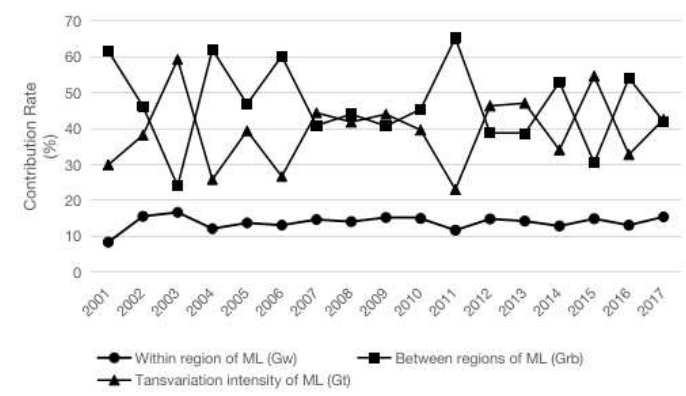

414 Fig. 6a Trend of CR of ML

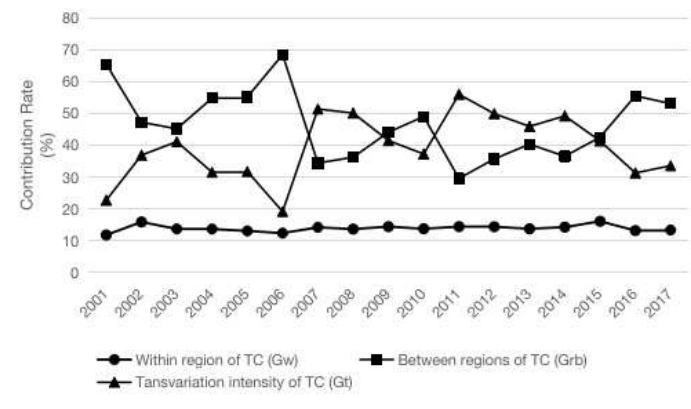

Fig. 6c Trend of CR of TC

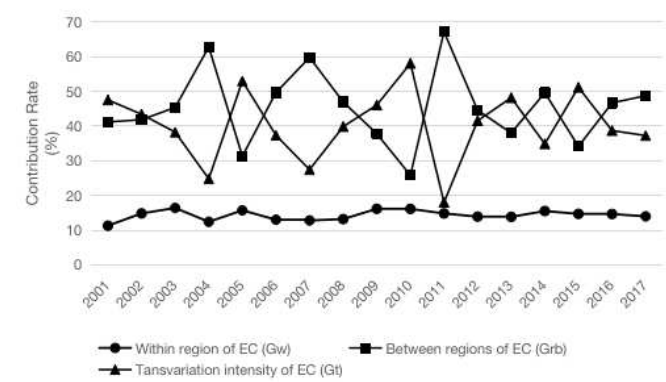

Fig. $6 \mathrm{~b}$ Trend of CR of EC

5. Expansion analysis: quantitative analysis of the sources of regional differences in China's ACE

\subsection{Stationarity test of variables}

The analysis provided explains the static relationship between ML, EC, and TC; however, it does not explain the dynamic relationship between these three factors, which requires a model. As EC and TC are generated by the decomposition of the ML index, there must be an internal connection between the three factors. The vector auto-regression (VAR) model allows each component to be an endogenous variable, and the time span of the data is 17 years, which meets the requirements of time series samples. Therefore, we used the PVAR model to test the dynamic relationships between the three factors. Before analyzing 
427 the PVAR model, it is necessary to test the stationarity of each variable and define the optimal post-order.

428 The test results are presented in Table $3^{8}$. The study found that the variables of each regional sample

429 showed a stationary series. Therefore, a direct model and analysis of the original data could be performed.

430

Table 3 Results of Stationarity test

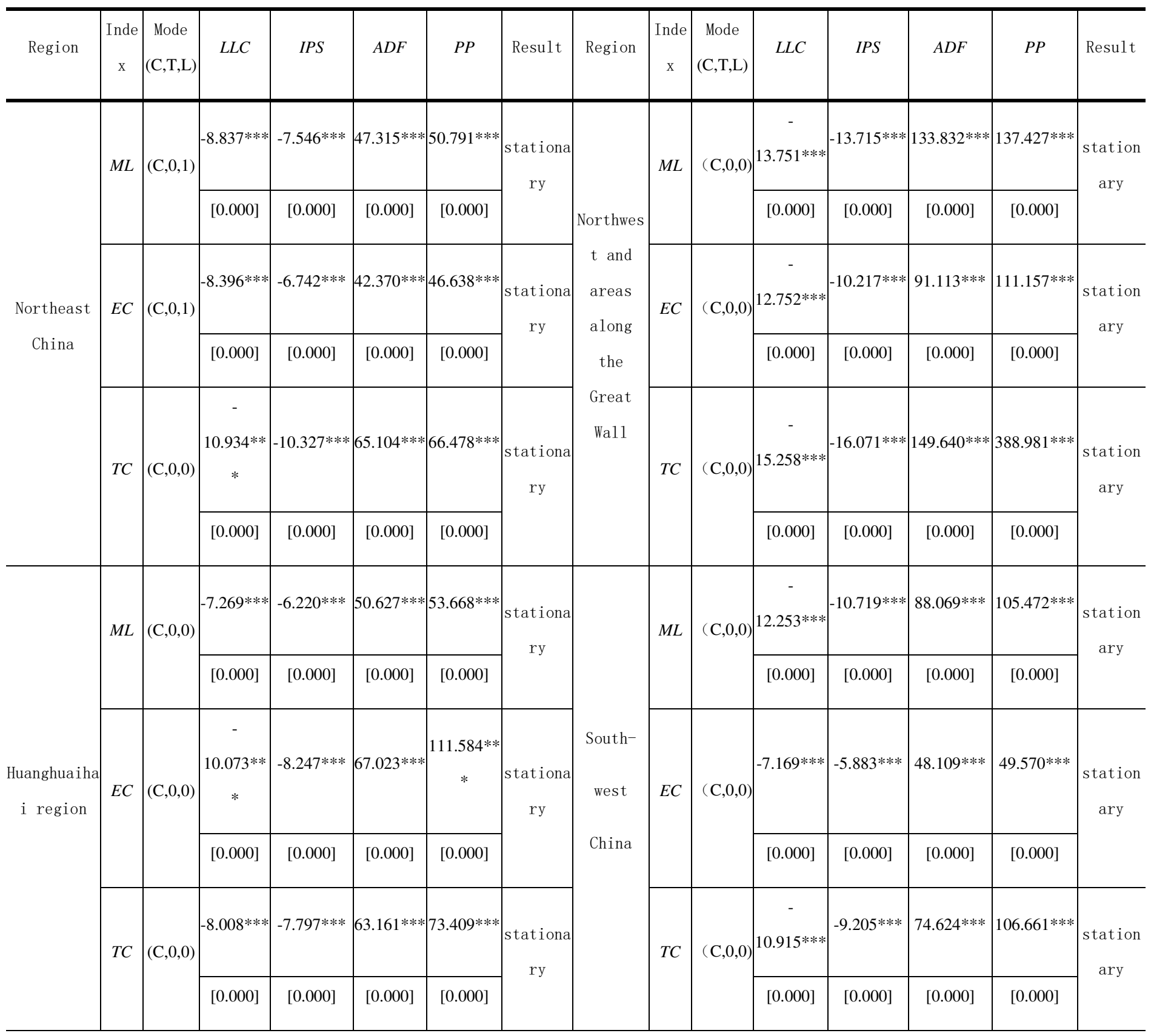

8 In the stationarity test, we selected the Levin, Lin, and Chu (LLC), Im, Pesaran, and Shin (IPS), augmented Dickey-Fuller (ADF), and Phillips-Perron (PP) test statistics to test whether each variable belonged to a stationary series. 


\begin{tabular}{|c|c|c|c|c|c|c|c|c|c|c|c|c|c|c|c|}
\hline \multirow{6}{*}{$\begin{array}{l}\text { Middle and } \\
\text { lower } \\
\text { reaches of }\end{array}$} & \multirow{2}{*}{$M L$} & \multirow{2}{*}{$(\mathrm{C}, 0,0)$} & $\begin{array}{c}- \\
11.866^{* * *}\end{array}$ & $-10.592 * * *$ & $101.494 * *$ & $219.296^{* *}$ & \multirow{2}{*}{$\begin{array}{c}\text { stationa } \\
\text { ry }\end{array}$} & \multicolumn{8}{|c|}{ Results of VAR Stationarity test } \\
\hline & & & {$[0.000]$} & {$[0.000]$} & {$[0.000]$} & {$[0.000]$} & & \multirow[b]{2}{*}{ Region } & \multirow[b]{2}{*}{$\begin{array}{c}\text { Inde } \\
\mathrm{x}\end{array}$} & \multirow[b]{2}{*}{$\begin{array}{c}\text { Mode } \\
(\mathrm{C}, \mathrm{T}, \mathrm{L})\end{array}$} & \multirow[b]{2}{*}{$\mathrm{ADF}$} & \multicolumn{3}{|c|}{ Test Level } & \multirow[b]{2}{*}{ Result } \\
\hline & \multirow[t]{2}{*}{$E C$} & \multirow[t]{2}{*}{$(\mathrm{C}, 0,0)$} & $\begin{array}{c}- \\
12.324 * * \\
*\end{array}$ & -11.119 & $\begin{array}{c}107.601 * * \\
*\end{array}$ & $\begin{array}{c}139.902 * * \\
*\end{array}$ & \multirow{2}{*}{$\begin{array}{c}\text { stationa } \\
\text { ry }\end{array}$} & & & & & $1 \%$ level & $5 \%$ level & $10 \%$ level & \\
\hline & & & {$[0.000]$} & {$[0.000]$} & {$[0.000]$} & {$[0.000]$} & & \multirow{6}{*}{$\begin{array}{l}\text { Qinghai- } \\
\text { Tibet } \\
\text { region }\end{array}$} & \multirow[b]{2}{*}{$M L$} & \multirow[b]{2}{*}{$(\mathrm{C}, 0,0)$} & $13.413 * * *$ & & & & \\
\hline & \multirow[t]{2}{*}{$T C$} & \multirow[t]{2}{*}{$(\mathrm{C}, 0,0)$} & $\left|\begin{array}{c}- \\
12.526^{* *} \\
*\end{array}\right|$ & $-12.567 * * *$ & $\begin{array}{c}122.554 * * \\
*\end{array}$ & $\begin{array}{c}126.709 * * \\
*\end{array}$ & \multirow{2}{*}{$\begin{array}{c}\text { stationa } \\
\text { ry }\end{array}$} & & & & {$[0.000]$} & -3.920 & -3.066 & -2.673 & ary \\
\hline & & & {$[0.000]$} & {$[0.000]$} & {$[0.000]$} & {$[0.000]$} & & & \multirow[t]{2}{*}{$E C$} & \multirow[t]{2}{*}{$(\mathrm{C}, 0,0)$} & $-7.370 * * *$ & \multirow[t]{2}{*}{-3.920} & \multirow[t]{2}{*}{-3.066} & \multirow[t]{2}{*}{-2.673} & \multirow{2}{*}{$\begin{array}{c}\text { station } \\
\text { ary }\end{array}$} \\
\hline \multirow{6}{*}{ South Chinal } & \multirow{2}{*}{$M L$} & \multirow{2}{*}{$(\mathrm{C}, 0,0)$} & $-6.075 * * *$ & $-5.092 * * *$ & $32.165 * * *$ & $33.022 * * *$ & \multirow[t]{2}{*}{ stationa } & & & & {$[0.000]$} & & & & \\
\hline & & & {$[0.000]$} & {$[0.000]$} & {$[0.000]$} & {$[0.000]$} & & & & & $-5.321 * * *$ & & & & station \\
\hline & $E C$ & $(\mathrm{C}, 0,0)$ & $-6.069 * * *$ & $-6.243 * * *$ & $39.203 * * *$ & $55.523 * * *$ & stationa & & & & [0.001] & & & & ary \\
\hline & & & [0.000] & {$[0.000]$} & {$[0.000]$} & {$[0.000]$} & ry & & & & & & & & \\
\hline & & & $-5.674 * * *$ & $-7.440 * * *$ & $46.735 * * *$ & $46.667 * * *$ & stationa & & & & & & & & \\
\hline & & & [0.000] & [0.000] & {$[0.000]$} & {$[0.000]$} & ry & & & & & & & & \\
\hline
\end{tabular}

431 Note: "*", "**", and "***" all indicate passing the test at the significance level of $10 \%, 5 \%$, and $1 \%$; the $\mathrm{P}$ value in

432 square brackets; the empirical results retain three decimal places.

\section{$433 \quad 5.2$ Granger causality test}

434 The above research shows that the data of ML, EC, and TC were stationary series. Thus, in this study, a 435 direct test was performed to evaluate whether there was Granger causality among the three factors.

436 Before the Granger causality test, the optimal lag order must be determined. To ensure the accuracy of 437 the research results, the optimal lag order was determined by adopting the test value that passed the most.

438 The results are listed in Table 4. The results of the Northeast China show that the changes in EC were 439 affected by changes in ML and TC, and their combined effects; the results in the Huanghuaihai region 440 show that there was a two-way Granger causality relationship between TC and ML, EC and TC, 441 manifested as the interaction between the two; EC and ML had a one-way Granger causality relationship, 442 manifested as changes in EC, which were affected by changes in ML; results in the middle and lower 443 reaches of the Yangtze River showed that ML and TC had a two-way Granger causality relationship. 444 However, there was only a one-way Granger causality relationship between EC and TC, which shows 445 that the change in TC was affected by the change in EC. Moreover, there was a two-way Granger 
447 causality relationship between TC and EC in the northwest and areas along the Great Wall; the

448 relationship between ML, TC, and EC was only manifested in that the changes in TC and EC were all

449 affected by changes in ML. The results in the Qinghai-Tibet region show that there was no interaction

450 between ML, EC, and TC.

Table 4 Result of Granger causality test

\begin{tabular}{|c|c|c|c|c|c|c|c|c|c|c|c|c|c|c|}
\hline \multirow[t]{2}{*}{ Null hypothesis } & \multicolumn{2}{|c|}{$\begin{array}{l}\text { Northeast } \\
\text { China }\end{array}$} & \multicolumn{2}{|c|}{$\begin{array}{l}\text { Huanghuaihai } \\
\text { region }\end{array}$} & \multicolumn{2}{|c|}{$\begin{array}{l}\text { Middle and lower } \\
\text { reaches of the } \\
\text { Yangtze River }\end{array}$} & \multicolumn{2}{|c|}{ South China } & \multicolumn{2}{|c|}{$\begin{array}{l}\text { Northwest and } \\
\text { areas along the } \\
\text { Great Wall }\end{array}$} & \multicolumn{2}{|c|}{ Southwest China } & \multicolumn{2}{|c|}{$\begin{array}{l}\text { Qinghai-Tibet } \\
\text { region }\end{array}$} \\
\hline & Ratio & Result & Ratio & Result & Ratio & Result & Ratio & Result & Ratio & Result & t Ratio & Result & Ratio & Result \\
\hline $\begin{array}{l}\text { The change in EC is not the cause of the } \\
\text { change in } M L \text { (df_A) }\end{array}$ & $\begin{array}{c}0.642 \\
{[0.423]}\end{array}$ & NO & $\begin{array}{l}0.041 \\
{[0.980]}\end{array}$ & NO & $\begin{array}{l}4.128 \\
{[0.127]}\end{array}$ & NO & $\begin{array}{c}14.552 * * * \\
{[0.000]}\end{array}$ & YES & $\begin{array}{l}0.903 \\
{[0.637]}\end{array}$ & NO & $\begin{array}{c}12.754 * * * \\
{[0.000]}\end{array}$ & YES & $\begin{array}{l}2.145 \\
{[0.342]}\end{array}$ & NO \\
\hline $\begin{array}{l}\text { The change in TC is not the cause of the } \\
\text { change in } M L \text { (df_A) }\end{array}$ & $\begin{array}{c}0.008 \\
{[0.929]}\end{array}$ & $\mathrm{NO}$ & $\begin{array}{c}9.596 * * * \\
{[0.008]}\end{array}$ & YES & $\begin{array}{c}32.832 * * * \\
{[0.000]}\end{array}$ & YES & $\begin{array}{c}12.310^{* * * *} \\
{[0.001]}\end{array}$ & YES & $\begin{array}{l}0.561 \\
{[0.755]}\end{array}$ & NO & $\begin{array}{c}11.394 * * * \\
{[0.001]}\end{array}$ & YES & {$\left[\begin{array}{c}0.865 \\
{[0.649]}\end{array}\right]$} & NO \\
\hline $\begin{array}{l}\text { The Changes in EC and TC are not the } \\
\text { cause of changes in } M L \text {, } \\
\text { Simultaneously (df_B) }\end{array}$ & $\begin{array}{l}5.105 * \\
{[0.078]}\end{array}$ & YES & $\begin{array}{c}15.882 * * * * \\
{[0.003]}\end{array}$ & YES & $\begin{array}{c}66.247 * * * \\
{[0.000]}\end{array}$ & YES & $\begin{array}{c}15.106 * * * \\
{[0.001]}\end{array}$ & YES & $\begin{array}{l}9.496 * * \\
{[0.050]}\end{array}$ & YES & $\begin{array}{c}12.780 * * * \\
{[0.002]}\end{array}$ & YES & {$\left[\begin{array}{c}3.627 \\
{[0.459]}\end{array}\right]$} & $\mathrm{NO}$ \\
\hline $\begin{array}{l}\text { The Changes in ML are not the cause of } \\
\text { changes in EC (df_A) }\end{array}$ & $\begin{array}{l}3.733 * \\
{[0.053]}\end{array}$ & YES & $\begin{array}{c}10.582 * * * \\
{[0.005]}\end{array}$ & YES & $\begin{array}{l}0.644 \\
{[0.725]}\end{array}$ & $\mathrm{NO}$ & $\begin{array}{l}4.823 * * \\
{[0.028]}\end{array}$ & YES & $\begin{array}{l}7.873 * * \\
{[0.020]}\end{array}$ & YES & $\begin{array}{c}0.027 \\
{[0.869]}\end{array}$ & NO & {$\left[\begin{array}{l}0.853 \\
{[0.653]}\end{array}\right.$} & NO \\
\hline $\begin{array}{l}\text { The change in TC growth is not the } \\
\text { cause of the change in EC (df_A) }\end{array}$ & $\begin{array}{c}6.849 * * * * \\
{[0.009]}\end{array}$ & YES & $\begin{array}{c}24.218 * * * \\
{[0.000]}\end{array}$ & YES & $\begin{array}{l}0.151 \\
{[0.927]}\end{array}$ & NO & $\begin{array}{l}6.110^{* * *} \\
{[0.013]}\end{array}$ & YES & $\begin{array}{l}7.780 * * \\
{[0.021]}\end{array}$ & YES & $\begin{array}{c}0.011 \\
{[0.918]}\end{array}$ & NO & {$\left[\begin{array}{c}1.005 \\
{[0.605]}\end{array}\right]$} & NO \\
\hline $\begin{array}{l}\text { The Changes in ML and TC are not the } \\
\text { cause of changes in EC, Simultaneously } \\
\left(d f_{-} \mathrm{B}\right)\end{array}$ & $\begin{array}{c}8.278 * * \\
{[0.016]}\end{array}$ & YES & $\begin{array}{c}25.536 * * * \\
{[0.000]}\end{array}$ & YES & $\begin{array}{l}1.823 \\
{[0.768]}\end{array}$ & NO & $\begin{array}{l}7.263 * * \\
{[0.027]}\end{array}$ & YES & $\begin{array}{l}8.154 * \\
{[0.086]}\end{array}$ & YES & $\begin{array}{c}0.121 \\
{[0.940]}\end{array}$ & NO & {$\left[\begin{array}{c}1.072 \\
{[0.899]}\end{array}\right]$} & $\mathrm{NO}$ \\
\hline $\begin{array}{l}\text { The change in ML is not the cause of the } \\
\text { change in TC (df_A) }\end{array}$ & $\begin{array}{c}0.125 \\
{[0.724]}\end{array}$ & NO & $\begin{array}{c}27.363 * * * \\
{[0.000]}\end{array}$ & YES & $\begin{array}{c}20.442 * * * \\
{[0.000]}\end{array}$ & YES & $\begin{array}{l}4.042 * * \\
{[0.044]}\end{array}$ & YES & $\begin{array}{c}15.997 * * * * \\
{[0.000]}\end{array}$ & YES & $\begin{array}{c}21.839 * * * \\
{[0.000]}\end{array}$ & YES & {$\left[\begin{array}{c}0.280 \\
{[0.870]}\end{array}\right.$} & $\mathrm{NO}$ \\
\hline $\begin{array}{l}\text { The Changes in EC are not the cause of } \\
\text { changes in TC (df_A) }\end{array}$ & $\begin{array}{c}0.013 \\
{[0.908]}\end{array}$ & NO & $\begin{array}{c}62.528 * * * \\
{[0.000]}\end{array}$ & YES & $\begin{array}{c}45.186^{* * * *} \\
{[0.000]}\end{array}$ & YES & $\begin{array}{l}6.465 * * \\
{[0.011]}\end{array}$ & YES & $\begin{array}{c}13.518 * * * \\
{[0.001]}\end{array}$ & YES & $\begin{array}{c}17.650 * * * \\
{[0.000]}\end{array}$ & YES & {$\left[\begin{array}{c}0.369 \\
{[0.831]}\end{array}\right.$} & $\mathrm{NO}$ \\
\hline $\begin{array}{l}\text { The Changes in } M L \text { and EC are not the } \\
\text { cause of changes in TC, Simultaneously } \\
\left(d f \_\mathrm{B}\right)\end{array}$ & $\begin{array}{c}0.338 \\
{[0.845]}\end{array}$ & NO & $\begin{array}{c}62.615 * * * \\
{[0.000]}\end{array}$ & YES & $\begin{array}{c}54.769 * * * \\
{[0.000]}\end{array}$ & YES & $\begin{array}{c}10.598 * * * \\
{[0.005]}\end{array}$ & YES & $\begin{array}{c}16.039 * * * \\
{[0.003]}\end{array}$ & YES & $\begin{array}{c}22.490 * * * \\
{[0.000]}\end{array}$ & YES & {$\left[\begin{array}{c}0.951 \\
{[0.917]}\end{array}\right]$} & $\mathrm{NO}$ \\
\hline$N$ & 48 & & 75 & & 105 & & 48 & & 90 & & 80 & & 15 & 5 \\
\hline$d f_{-} \mathrm{A}$ & 1 & & 2 & & 2 & & 1 & & 2 & & 1 & & 2 & , \\
\hline
\end{tabular}




\begin{tabular}{|c|c|c|c|c|c|c|c|}
\hline$d f \_\mathrm{B}$ & 2 & 4 & 4 & 2 & 4 & 2 & 4 \\
\hline
\end{tabular}

Note: "*", "**" and "***" all indicate that the test passed the test at the significance level of $10 \%, 5 \%$, and $1 \%$; the

453 P value in brackets; YES and NO respectively indicate whether the test passed or not. The empirical results retain

454 three decimal places.

455 5.3 PVAR model analysis of the dynamic efficiency of China's ACE

456 Based on the above evaluation, the PVAR model system OLS of ML, EC, and TC, and the test results

457 are shown in Table 5. The results in Northeast China show that ML significantly inhibited the 458 development of EC during lag phase 1, whereas TC promoted the development of EC. In South China,

459 ML had a self-weakening mechanism, and EC and TC had significant positive effects on ML. 460 Furthermore, ML had an inhibitory effect on the development of EC, whereas TC had a promoting effect.

461 In addition, ML had an inhibitory effect on TC development. In the middle and lower reaches of the 462 Yangtze River, ML and EC had a self-weakening mechanism, but EC had a long-term self-weakening 463 mechanism, whereas TC had a self-reinforcing mechanism. In the Huanghuaihai zone, TC had a 464 significant positive impact on ML in the lag phase 2. In addition, EC had a self-weakening mechanism, 465 whereas TC had a non-linear change mechanism, which was manifested as a self-enhancement at the 466 initial stage and a self-weakening mechanism at the later stage. In the Northwest and areas along the 467 Great Wall, both ML and EC had a self-weakening mechanism, but the self-weakening mechanism of 468 EC lasted for a long time, whereas TC had a lagging self-enhancement mechanism. In addition, ML had 469 a continuous weakening inhibitory effect on TC, and the promotion effect of ML on EC had a long 470 hysteresis effect. In Southwest China, ML had a self-weakening mechanism, and both TC and EC that 471 lagged in the first stage had a significant positive impact; moreover, TC had a self-reinforcing mechanism, 472 which could effectively inhibit the development of TC, but the growth of EC drove the growth of TC. In 473 the Qinghai-Tibet region, there was no correlation between ML, EC, and TC.

Table 5 Results of OLS

\begin{tabular}{|c|c|c|c|c|c|c|c|c|c|}
\hline \multirow{6}{*}{ Northeast China } & $\operatorname{ML}(-1)$ & -0.449 & $-0.646 *$ & -0.148 & \multirow{6}{*}{ South China } & $\operatorname{ML}(-1)$ & $-2.408 * * *$ & $-1.221 * *$ & $-1.203 * *$ \\
\hline & & $(0.359)$ & $(0.334)$ & $(0.418)$ & & & $(0.653)$ & $(0.556)$ & $(0.598)$ \\
\hline & & $(0.389)$ & $(0.363)$ & $(0.453)$ & & & $(0.683)$ & $(0.581)$ & $(0.625)$ \\
\hline & $\mathrm{TC}(-1)$ & -0.029 & $0.796 * * *$ & -0.517 & & $\mathrm{TC}(-1)$ & $2.442 * * *$ & $1.463 * *$ & 1.019 \\
\hline & $\mathrm{C}$ & $1.279 * * *$ & 0.305 & $1.773 * * *$ & & $\mathrm{C}$ & $-1.614 * *$ & -0.235 & -0.364 \\
\hline & & $(0.405)$ & $(0.377)$ & $(0.472)$ & & & $(0.747)$ & $(0.635)$ & $(0.684)$ \\
\hline
\end{tabular}




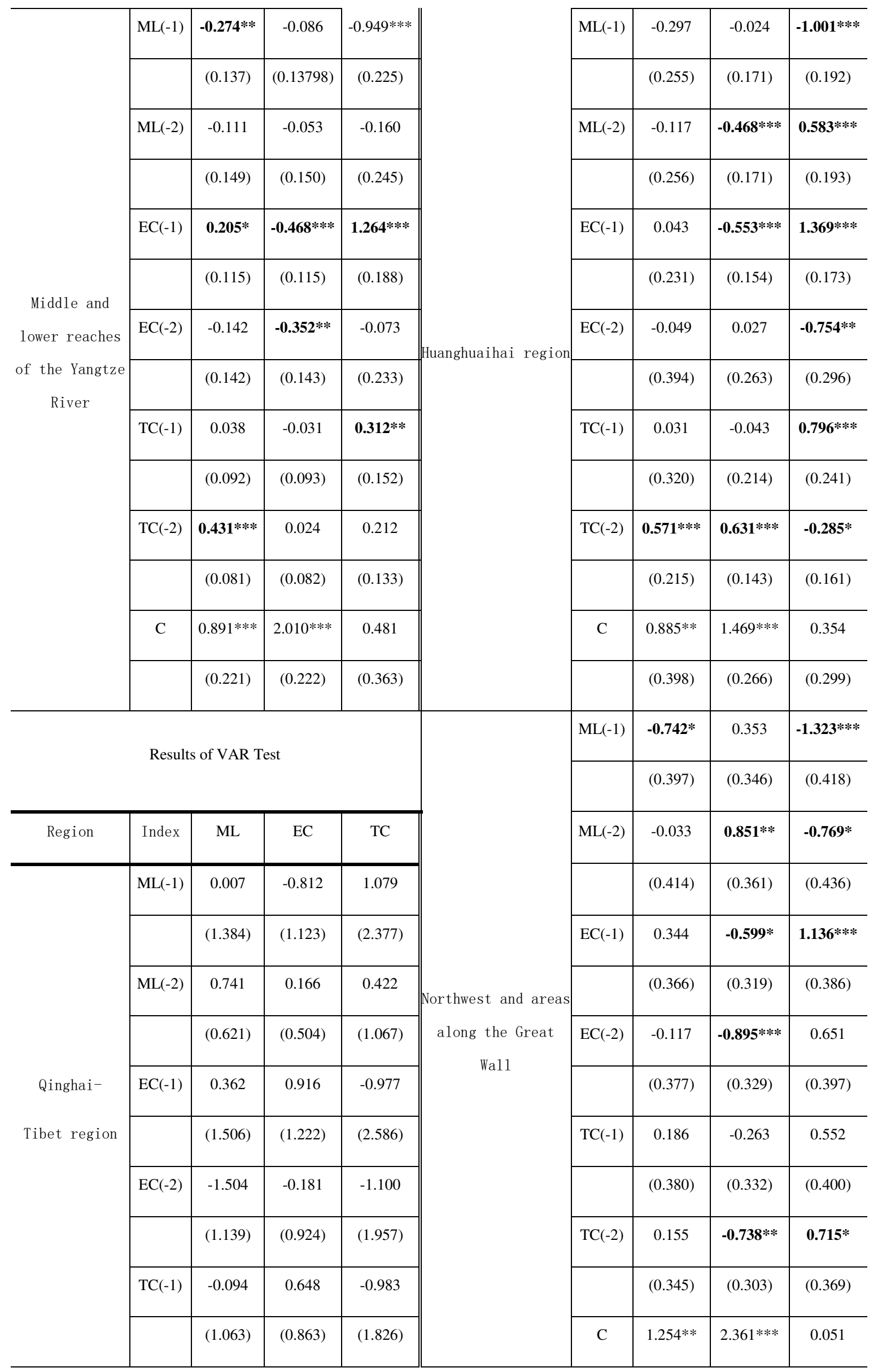




\begin{tabular}{|c|c|c|c|c|c|c|c|c|}
\hline $\mathrm{TC}(-2)$ & -0.588 & -0.255 & -0.148 & & & $(0.488)$ & $(0.426)$ & $(0.514)$ \\
\hline & $(0.637)$ & $(0.517)$ & (1.094) & \multirow{8}{*}{ Southwest China } & $\operatorname{ML}(-1)$ & $-2.142 * * *$ & 0.066 & $-2.678 * * *$ \\
\hline $\mathrm{C}$ & 2.011 & 0.432 & 2.762 & & & $(0.501)$ & $(0.398)$ & $(0.573)$ \\
\hline & $(1.860)$ & (1.509) & (3.195) & & $\mathrm{EC}(-1)$ & $1.987 * * *$ & -0.134 & $2.674 * * *$ \\
\hline & & & & & & $(0.556)$ & $(0.442)$ & $(0.636)$ \\
\hline & & & & & $\mathrm{TC}(-1)$ & $1.575 * * *$ & -0.038 & $2.004 * * *$ \\
\hline & & & & & & $(0.467)$ & $(0.371)$ & $(0.534)$ \\
\hline & & & & & $\mathrm{C}$ & -0.364 & $1.144 * * *$ & -0.970 \\
\hline & & & & & & $(0.544)$ & $(0.432)$ & $(0.622)$ \\
\hline
\end{tabular}
standard errors are in parentheses.

\subsection{Impulse analysis and variance decomposition of the dynamic efficiency of China's ACE}

478 Figures 7-13 show the results of impulse response between ML, EC, and TC in seven major agricultural zones in China, where the abscissa is the number of response periods of impact action, which was set to 10. The ordinate represents the degree of influence of the variables. The curve in the figure represents the impulse response function, and the curves on both sides represent the estimated values of the $95 \%$ and $5 \%$ quantile points, respectively.

483 Figure 7 shows that in the Northeast China, there were significant differences in the response of ML to EC and TC shocks. The response to EC shocks showed an initial positive effect, followed by a negative effect, and the intensity of volatility was weakened. In contrast, the impact of EC on ML and TC was also different. Moreover, the response to ML shock exhibited a continuously weakened positive effect at the initial stage, then turned to a negative effect, and then rebounded. The response to the TC shock showed a continuously increasing positive effect at the initial stage, followed by some small fluctuations. In contrast, in the impulse response analysis of TC, the impacts of ML and EC on TC exhibited severe fluctuations, and the fluctuation directions were completely opposite. 

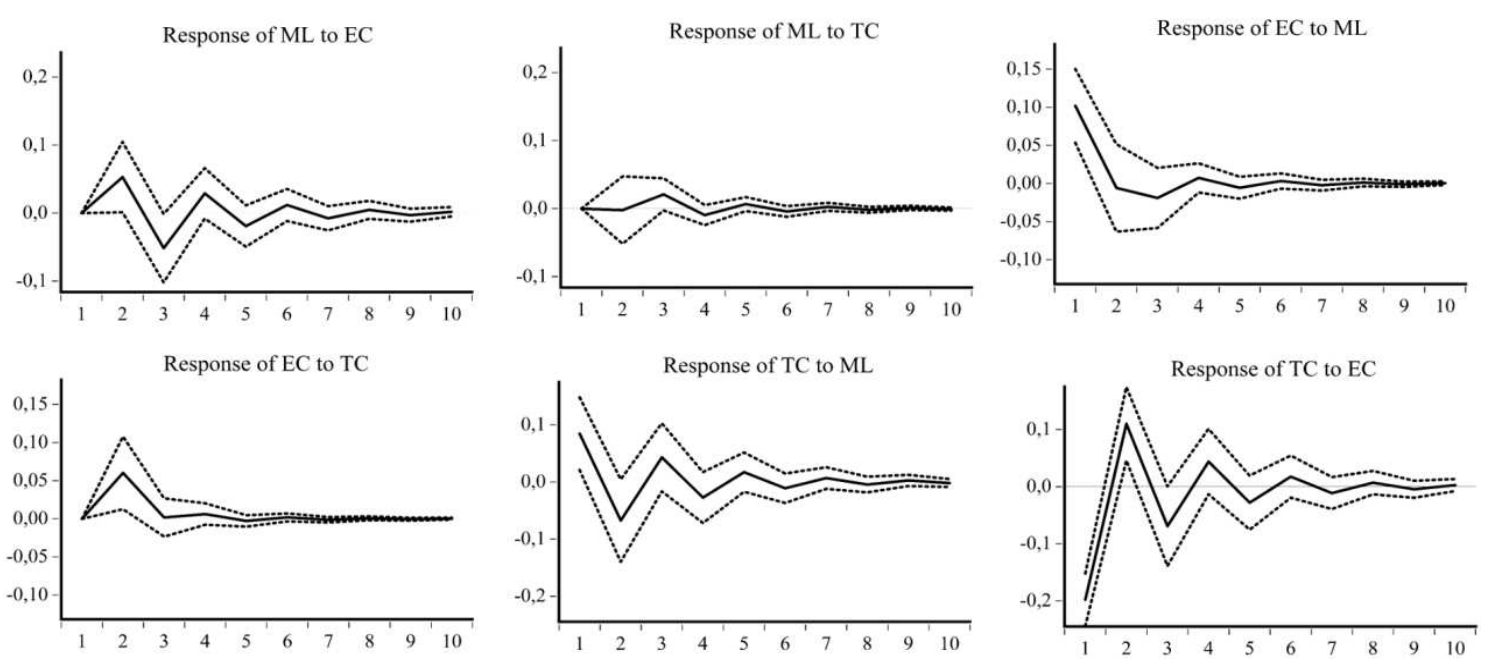

Fig. 7 Impulse response results of ML, EC, and TC of AEC emissions in Northeast China

Figure 8 shows that in the Huanghuaihai region, the ML response to EC and TC shocks had a large lag; at the same time, there were opposite fluctuations. In the second period, the ML response to EC shocks showed an initially negative followed by a positive effect, the intensity first increased, then decreased, and finally increased again. The reaction of ML to TC shock was the opposite, and the reaction intensity was weak. In the analysis of EC impulse response, the EC response to ML shock showed an initially positive effect followed by a negative effect. Furthermore, the EC response to TC shock had a large hysteresis, which first manifested in the second phase, and showed an initially positive followed by a negative effect. In addition, in the TC impulse response analysis, the TC response to ML and EC shocks was severe. The response to ML shock showed an initially positive effect followed by a negative effect, and the intensity gradually weakened. However, the response to the EC shock showed an initially negative followed by a positive effect, and the weakening of the intensity was not evident; finally, it remained as a positive effect.
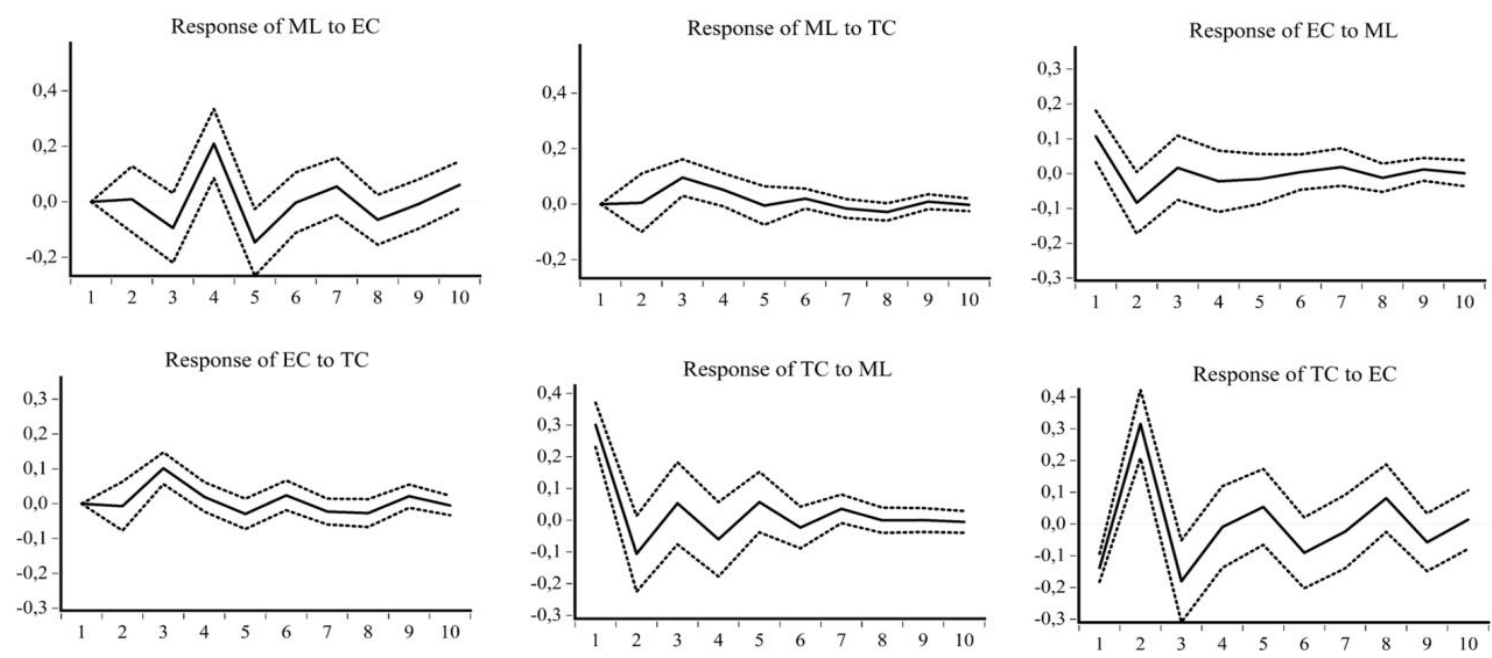

508 Fig. 8 Impulse response results of ML, EC, and TC of AEC emissions in the Huanghuaihai region 
510 Figure 9 shows that in the middle and lower reaches of the Yangtze River, the response of ML to EC

511 shocks showed an initially positive followed by a negative effect, and the intensity first increased and 512 then decreased. In addition, the response to TC shocks showed an initially positive followed by a negative

513 effect, and the intensity gradually weakened. Moreover, in the analysis of EC impulse response, the EC

514 response to ML shock showed an initially positive followed by a negative fluctuation, whereas the

515 response to TC shock was weak. Furthermore, in the impulse response analysis of TC, the response of

516 TC to the shock of ML and EC was severe. In contrast, the reaction to ML shock showed an initially

517 positive effect followed by a negative effect, and the intensity gradually weakened, whereas the reaction

518 to EC shock showed an initially negative followed by a positive effect, and the intensity gradually

519 weakened as well.
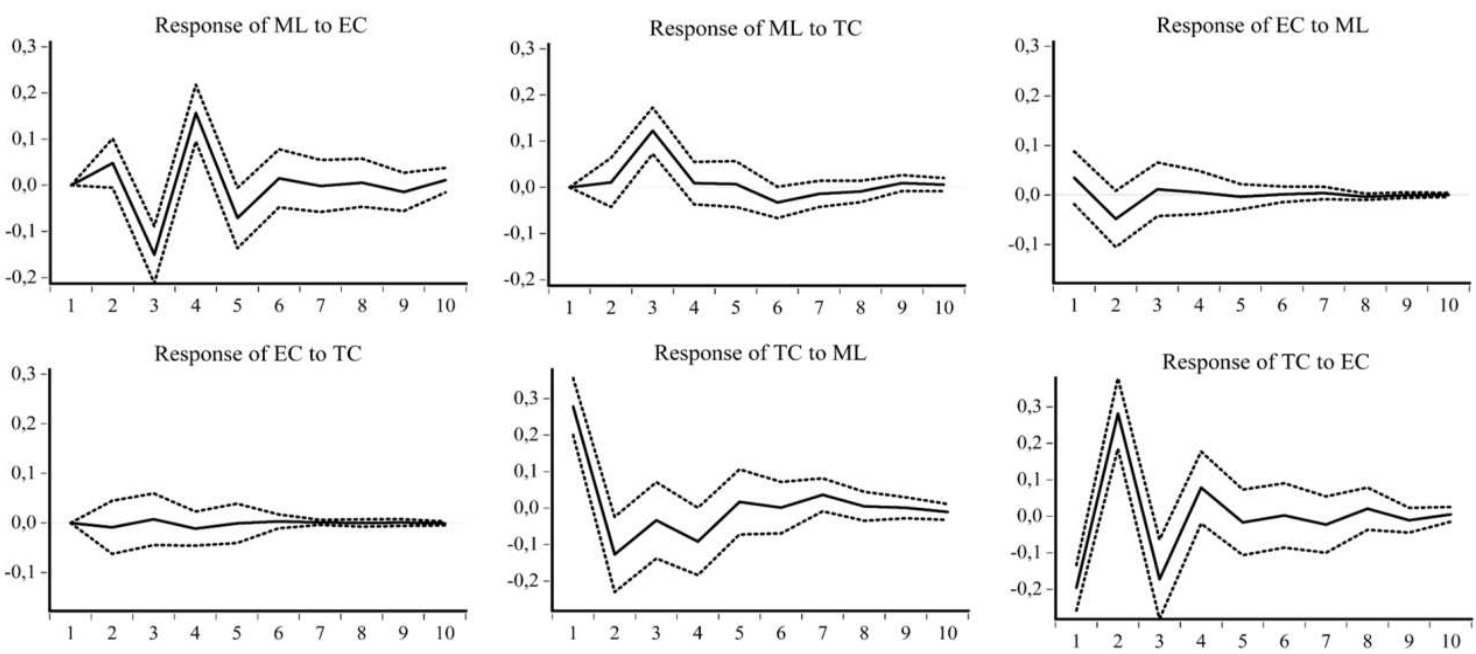

521 Fig. 9 Impulse response results of ML, EC, and TC of AEC emissions in the middle and lower reaches

522 of the Yangtze River

524 Figure 10 shows that in South China, the response of ML to EC shocks showed an initially positive followed by a negative effect, with the intensity first increasing and then decreasing. At the same time,

526 the response to TC shocks showed a continuous positive effect, the intensity first increased and then decreased. Moreover, in the analysis of EC impulse response, the EC response to ML shock showed a continuous weakening positive effect, whereas the response to TC shock showed a continuous positive effect, with the intensity first increasing and then decreasing. Furthermore, in the impulse response analysis of TC, the response of TC to ML shock showed a continuously weakening positive effect, whereas the response to EC shock was very severe, showing an initially negative followed by a positive effect, and the intensity gradually weakened. 

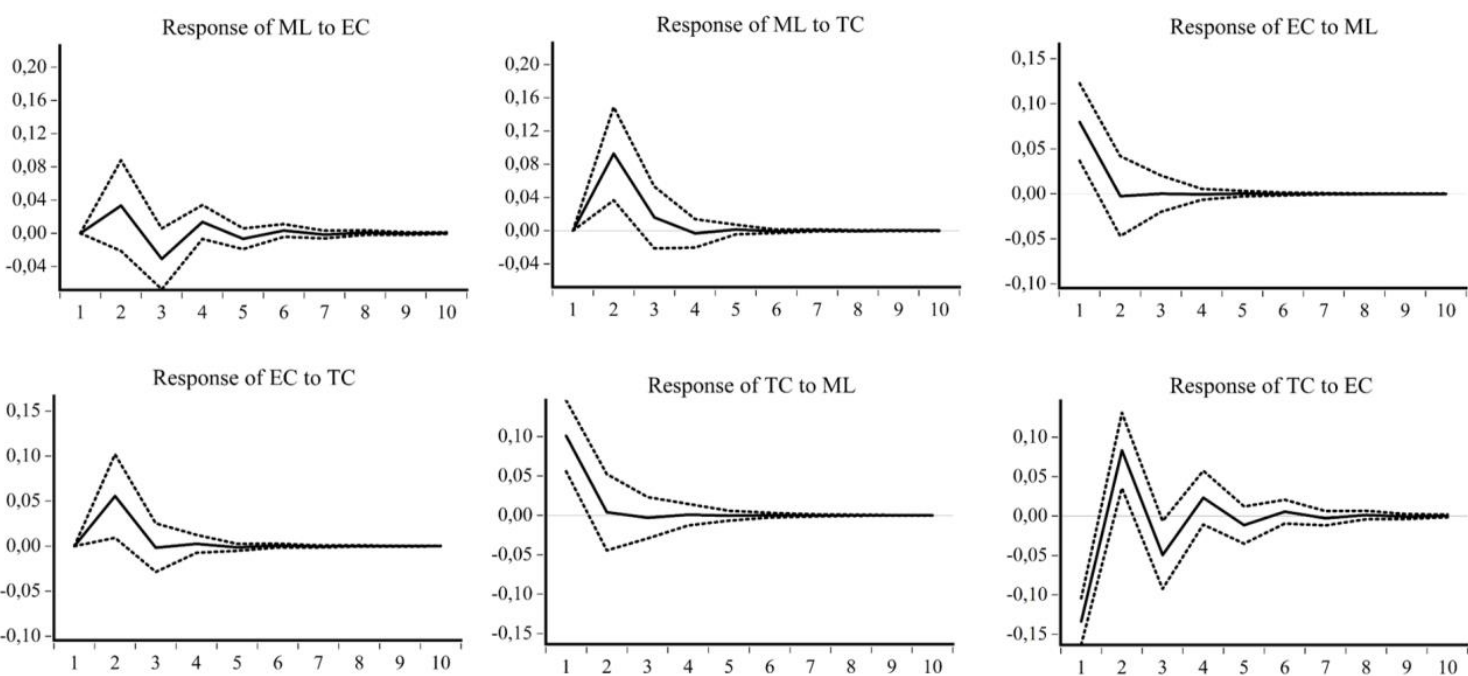

534 Fig. 10 Impulse response results of ML, EC, and TC of AEC emissions in South China

Figure 11 shows that in the Northwest and along the Great Wall, ML reacted violently to EC shocks, showing a fluctuating pattern of alternating positive and negative effects. Although the intensity weakened, it was not evident. In addition, the response to the TC shock was not significant. In the analysis of EC impulse response, EC showed a continuously weakening positive effect on ML shock. The response to TC shock showed a continuously increasing negative effect at the initial stage, and then rebounded to its peak in the fourth period, showing a positive effect. Furthermore, in the impulse response analysis of TC, the response of TC to ML and EC shocks was severe. Moreover, the response to the ML

543 shock showed an initially positive followed by a negative effect, and the intensity gradually weakened,

544 whereas the response to the EC shock showed an initially negative followed by a positive effect, the 545 intensity gradually weakened, and finally the shock effect remained positive.
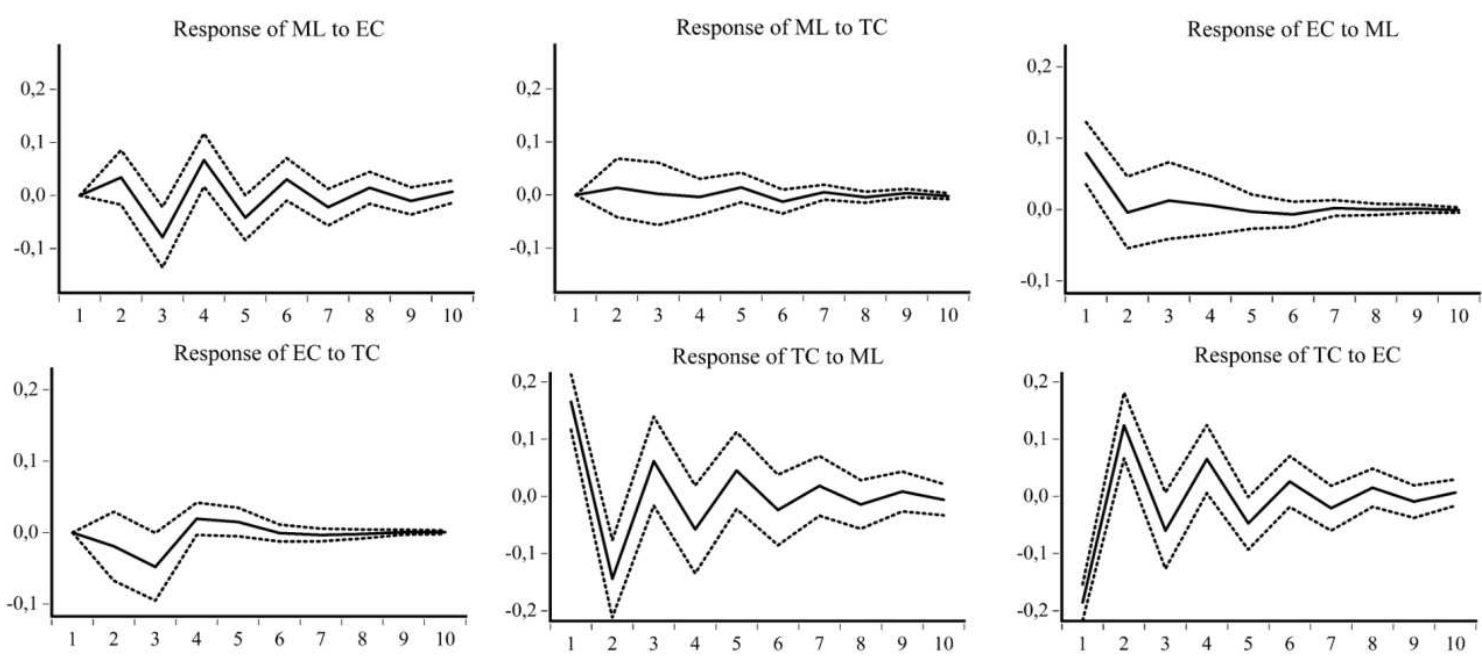

Fig. 11 Impulse response results of ML, EC, and TC of AEC emissions in the Northwest and along the

548 Great Wall 
Figure 12 shows that in the Southwest China, the response of ML to EC shocks showed a continuous positive effect, with the intensity first increasing and then decreasing. At the same time, the response to the TC shock showed an initially positive followed by a negative effect, and the intensity first increased and then decreased. Moreover, in the analysis of EC impulse response, the response of EC to ML shock showed a continuously weakening positive effect, whereas the intensity of response to TC shock was around zero. In contrast, in the impulse response analysis of TC, the response of TC to the shock of ML and EC was severe. Furthermore, the response to ML shock showed an initially positive followed by a negative effect, and the intensity first decreased, then increased, and decreased again, whereas the response to the EC shock showed an initially negative followed by a positive effect, and the intensity first increased and then decreased.
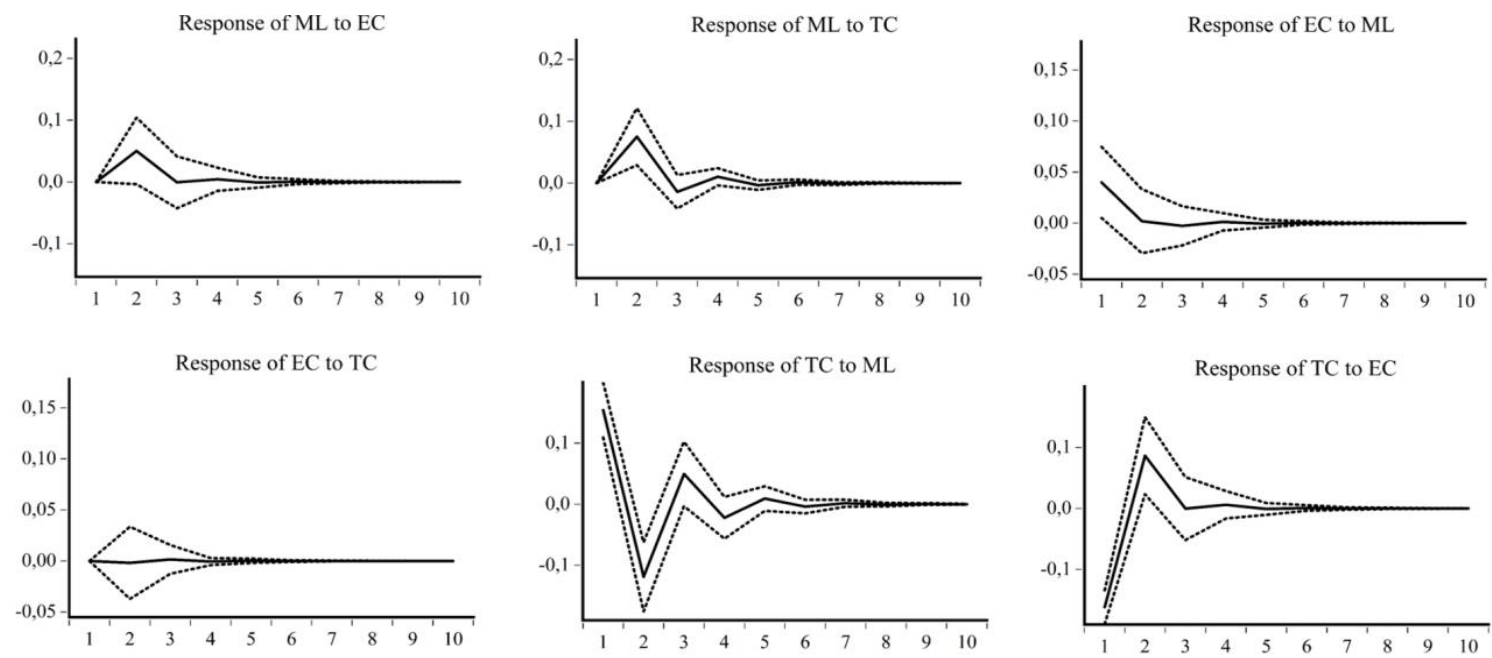

561 Fig. 12 Impulse response results of ML, EC, and TC of AEC emissions in Southwest China

Figure 13 shows that in the Qinghai-Tibet region, the response of ML to EC shocks showed an initially positive followed by a negative effect, and the intensity first increased and then decreased. In addition, the response to TC shocks was weaker, there was a large hysteresis effect, and the negative effect was first identified in the third period. Moreover, in the analysis of EC impulse response, the EC response to ML shock showed an initially positive followed by a negative effect, and the intensity first increased and then decreased, whereas the response to TC shock showed a steady positive effect at the initial stage, and then showed a positive effect. In contrast, in the impulse response analysis of TC, the response of TC to ML and EC shocks was severe. Moreover, the response to the ML shock showed an initially positive

571 followed by a negative effect, and the intensity gradually weakened, whereas the response to EC shocks showed an initially negative followed by a positive effect, and the intensity gradually weakened. 

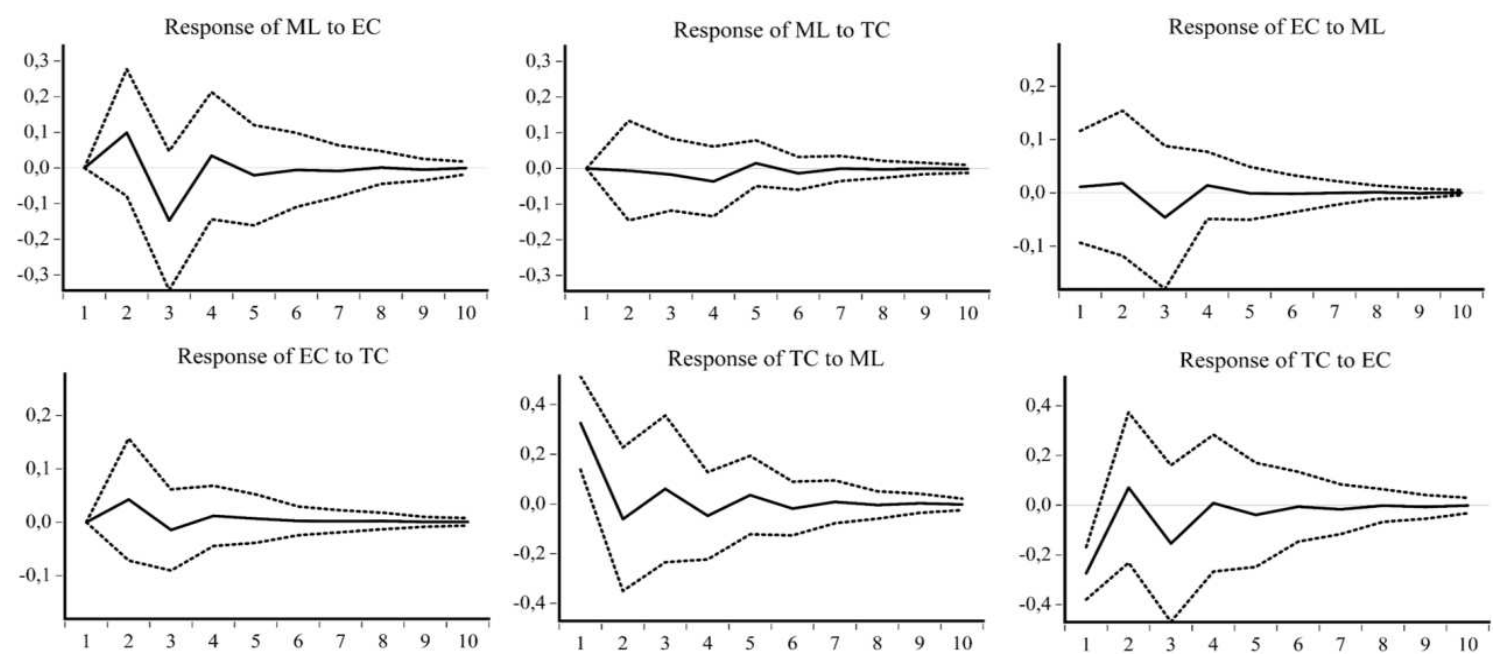

575 Fig. 13 Impulse response results of ML, EC, and TC of AEC emissions in the Qinghai-Tibet region

Table 6 shows that for the variance decomposition of the ML of ACE in the seven major agricultural regions of China, ML was 100\% affected by its own fluctuation shock in the first period, and the impact of EC and TC on ML was first identified in the second period. Except for the Southwest region, the impact of EC on ML in other regions was higher than the impact of TC on ML, and the impact strength continued to increase, indicating that the impact of EC on ML was lagging, long-term, and continuous. In the variance decomposition of EC and TC, each region also had certain commonalities. First, the impact of ML on EC was manifested in the first period, and the impact of TC on EC was first identified in the second period. Second, the impact strength of TC to EC was very small, ranging from $0.013 \%$ to $9.654 \%$. Third, the impact of ML and EC on TC was first identified in the first period. Fourth, except for certain periods, the impact of TC on itself was considerably smaller than the impact of ML and EC on $\mathrm{TC}$, which indicates that the development of TC depends on changes in ML and EC.

Table 6 Results of Variance decomposition

\begin{tabular}{|c|c|c|c|c|c|c|c|c|c|c|c|c|}
\hline \multirow{3}{*}{ Period } & \multicolumn{12}{|c|}{ Northeast China } \\
\hline & \multicolumn{4}{|c|}{ Variance decomposition of ML } & \multicolumn{4}{|c|}{ Variance decomposition of EC } & \multicolumn{4}{|c|}{ Variance decomposition of TC } \\
\hline & S.E. & ML & EC & $\mathrm{TC}$ & S.E. & ML & $\mathrm{EC}$ & $\mathrm{TC}$ & S.E. & ML & $\mathrm{EC}$ & $\mathrm{TC}$ \\
\hline 1 & 0.196 & 100.000 & 0.000 & 0.000 & 0.182 & 31.251 & 68.749 & 0.000 & 0.228 & 13.772 & 75.191 & 11.037 \\
\hline 2 & 0.211 & 93.703 & 6.286 & 0.011 & 0.208 & 24.205 & 67.350 & 8.446 & 0.265 & 16.660 & 72.978 & 10.362 \\
\hline 3 & 0.220 & 87.820 & 11.263 & 0.918 & 0.209 & 24.731 & 66.917 & 8.353 & 0.278 & 17.525 & 72.345 & 10.130 \\
\hline 4 & 0.223 & 86.257 & 12.665 & 1.077 & 0.210 & 24.675 & 66.943 & 8.382 & 0.284 & 17.816 & 72.130 & 10.055 \\
\hline 5 & 0.224 & 85.596 & 13.249 & 1.155 & 0.210 & 24.684 & 66.938 & 8.378 & 0.286 & 17.928 & 72.047 & 10.025 \\
\hline 6 & 0.224 & 85.340 & 13.476 & 1.184 & 0.210 & 24.685 & 66.937 & 8.378 & 0.286 & 17.972 & 72.014 & 10.014 \\
\hline
\end{tabular}




\begin{tabular}{|c|c|c|c|c|c|c|c|c|c|c|c|c|}
\hline 7 & 0.225 & 85.238 & 13.566 & 1.196 & 0.210 & 24.685 & 66.937 & 8.378 & 0.287 & 17.990 & 72.001 & 10.009 \\
\hline 8 & 0.225 & 85.196 & 13.603 & 1.201 & 0.210 & 24.685 & 66.937 & 8.378 & 0.287 & 17.997 & 71.996 & 10.007 \\
\hline 9 & 0.225 & 85.180 & 13.617 & 1.203 & 0.210 & 24.685 & 66.937 & 8.378 & 0.287 & 17.999 & 71.994 & 10.007 \\
\hline 10 & 0.225 & 85.173 & 13.623 & 1.203 & 0.210 & 24.685 & 66.937 & 8.378 & 0.287 & 18.001 & 71.993 & 10.006 \\
\hline \multirow{3}{*}{ Period } & \multicolumn{12}{|c|}{ Huanghuaihai region } \\
\hline & \multicolumn{4}{|c|}{ Variance decomposition of ML } & \multicolumn{4}{|c|}{ Variance decomposition of EC } & \multicolumn{4}{|c|}{ Variance decomposition of TC } \\
\hline & S.E. & ML & $\mathrm{EC}$ & $\mathrm{TC}$ & S.E. & ML & EC & $\mathrm{TC}$ & S.E. & ML & $\mathrm{EC}$ & $\mathrm{TC}$ \\
\hline 1 & 0.491 & 100.000 & 0.000 & 0.000 & 0.328 & 10.599 & 89.401 & 0.000 & 0.369 & 66.331 & 13.937 & 19.732 \\
\hline 2 & 0.509 & 99.957 & 0.033 & 0.010 & 0.377 & 12.935 & 87.031 & 0.035 & 0.514 & 38.493 & 44.850 & 16.656 \\
\hline 3 & 0.545 & 93.875 & 3.016 & 3.109 & 0.391 & 12.219 & 80.987 & 6.794 & 0.549 & 34.695 & 50.102 & 15.203 \\
\hline 4 & 0.592 & 81.496 & 15.105 & 3.399 & 0.441 & 9.887 & 84.558 & 5.555 & 0.554 & 35.188 & 49.153 & 15.659 \\
\hline 5 & 0.610 & 76.901 & 19.898 & 3.201 & 0.479 & 8.468 & 86.457 & 5.075 & 0.560 & 35.497 & 49.051 & 15.452 \\
\hline 6 & 0.612 & 76.884 & 19.821 & 3.295 & 0.480 & 8.454 & 86.236 & 5.310 & 0.570 & 34.437 & 49.896 & 15.667 \\
\hline 7 & 0.615 & 76.309 & 20.373 & 3.318 & 0.491 & 8.233 & 86.481 & 5.287 & 0.572 & 34.639 & 49.783 & 15.578 \\
\hline 8 & 0.620 & 75.346 & 21.178 & 3.477 & 0.504 & 7.863 & 86.837 & 5.300 & 0.578 & 33.942 & 50.770 & 15.288 \\
\hline 9 & 0.620 & 75.345 & 21.163 & 3.492 & 0.505 & 7.889 & 86.650 & 5.461 & 0.581 & 33.604 & 51.243 & 15.152 \\
\hline 10 & 0.623 & 74.623 & 21.917 & 3.460 & 0.510 & 7.742 & 86.890 & 5.369 & 0.581 & 33.546 & 51.198 & 15.256 \\
\hline \multirow{3}{*}{ Period } & \multicolumn{12}{|c|}{ Middle and lower reaches of the Yangtze River } \\
\hline & \multicolumn{4}{|c|}{ Variance decomposition of ML } & \multicolumn{4}{|c|}{ Variance decomposition of EC } & \multicolumn{4}{|c|}{ Variance decomposition of TC } \\
\hline & S.E. & ML & $\mathrm{EC}$ & $\mathrm{TC}$ & S.E. & ML & $\mathrm{EC}$ & $\mathrm{TC}$ & S.E. & ML & EC & $\mathrm{TC}$ \\
\hline 1 & 0.272 & 100.000 & 0.000 & 0.000 & 0.273 & 1.614 & 98.386 & 0.000 & 0.446 & 38.982 & 19.273 & 41.745 \\
\hline 2 & 0.282 & 96.940 & 2.912 & 0.148 & 0.303 & 3.846 & 96.070 & 0.085 & 0.550 & 30.964 & 38.928 & 30.108 \\
\hline 3 & 0.353 & 67.806 & 19.993 & 12.200 & 0.308 & 3.850 & 96.010 & 0.140 & 0.581 & 28.055 & 43.631 & 28.314 \\
\hline 4 & 0.391 & 57.789 & 32.240 & 9.971 & 0.322 & 3.558 & 96.187 & 0.255 & 0.597 & 28.898 & \begin{tabular}{|l|}
43.017 \\
\end{tabular} & 28.085 \\
\hline 5 & 0.398 & 55.973 & 34.350 & 9.678 & 0.324 & 3.527 & 96.220 & 0.253 & 0.600 & 28.730 & 42.727 & 28.543 \\
\hline 6 & 0.400 & 55.773 & 34.018 & 10.209 & 0.324 & 3.521 & 96.218 & 0.262 & 0.601 & 28.612 & 42.552 & 28.835 \\
\hline 7 & 0.401 & 55.788 & 33.912 & 10.301 & 0.325 & 3.521 & 96.217 & 0.262 & 0.603 & 28.822 & 42.464 & 28.714 \\
\hline
\end{tabular}




\begin{tabular}{|c|c|c|c|c|c|c|c|c|c|c|c|c|}
\hline 8 & 0.401 & 55.750 & 33.907 & 10.342 & 0.325 & 3.531 & 96.208 & 0.262 & 0.603 & 28.773 & 42.503 & 28.723 \\
\hline 9 & 0.402 & 55.691 & 33.942 & 10.367 & 0.325 & 3.529 & 96.209 & 0.262 & 0.603 & 28.740 & 42.485 & 28.776 \\
\hline 10 & 0.402 & 55.637 & 33.985 & 10.378 & 0.325 & 3.527 & 96.209 & 0.263 & 0.604 & 28.759 & 42.475 & 28.766 \\
\hline \multirow{3}{*}{ Period } & \multicolumn{12}{|c|}{ South China } \\
\hline & \multicolumn{4}{|c|}{ Variance decomposition of ML } & \multicolumn{4}{|c|}{ Variance decomposition of EC } & \multicolumn{4}{|c|}{ Variance decomposition of TC } \\
\hline & S.E. & ML & $\mathrm{EC}$ & $\mathrm{TC}$ & S.E. & ML & $\mathrm{EC}$ & $\mathrm{TC}$ & S.E. & ML & EC & $\mathrm{TC}$ \\
\hline 1 & 0.187 & 100.000 & 0.000 & 0.000 & 0.159 & 25.002 & 74.998 & 0.000 & 0.172 & 34.523 & 60.577 & 4.900 \\
\hline 2 & 0.212 & 78.337 & 2.466 & 19.197 & 0.179 & 19.860 & 70.485 & 9.654 & 0.195 & 26.863 & 65.378 & 7.759 \\
\hline 3 & 0.214 & 76.287 & 4.475 & 19.238 & 0.180 & 19.539 & 70.953 & 9.508 & 0.201 & 25.098 & 67.015 & 7.887 \\
\hline 4 & 0.215 & 75.966 & 4.853 & 19.181 & 0.181 & 19.452 & 71.063 & 9.485 & 0.203 & 24.751 & 67.401 & 7.848 \\
\hline 5 & 0.215 & 75.891 & 4.944 & 19.166 & 0.181 & 19.431 & 71.089 & 9.480 & 0.203 & 24.669 & 67.493 & 7.838 \\
\hline 6 & 0.215 & 75.872 & 4.966 & 19.162 & 0.181 & 19.426 & 71.096 & 9.479 & 0.203 & 24.649 & 67.515 & 7.835 \\
\hline 7 & 0.215 & 75.868 & 4.971 & 19.162 & 0.181 & 19.424 & 71.097 & 9.478 & 0.203 & 24.645 & 67.521 & 7.835 \\
\hline 8 & 0.215 & 75.866 & 4.972 & 19.161 & 0.181 & 19.424 & 71.098 & 9.478 & 0.203 & 24.643 & 67.522 & 7.835 \\
\hline 9 & 0.215 & 75.866 & 4.972 & 19.161 & 0.181 & 19.424 & 71.098 & 9.478 & 0.203 & 24.643 & 67.522 & 7.835 \\
\hline 10 & 0.215 & 75.866 & 4.973 & 19.161 & 0.181 & 19.424 & 71.098 & 9.478 & 0.203 & 24.643 & 67.522 & 7.835 \\
\hline \multirow{3}{*}{ Period } & \multicolumn{12}{|c|}{ Northwest and areas along the Great Wall } \\
\hline & \multicolumn{4}{|c|}{ Variance decomposition of ML } & \multicolumn{4}{|c|}{ Variance decomposition of EC } & \multicolumn{4}{|c|}{ Variance decomposition of TC } \\
\hline & S.E. & ML & $\mathrm{EC}$ & $\mathrm{TC}$ & S.E. & ML & EC & $\mathrm{TC}$ & S.E. & ML & EC & $\mathrm{TC}$ \\
\hline 1 & 0.245 & 100.000 & 0.000 & 0.000 & 0.214 & 13.556 & 86.444 & 0.000 & 0.259 & 40.819 & 51.278 & 7.903 \\
\hline 2 & 0.277 & 98.261 & 1.502 & 0.237 & 0.226 & 12.166 & 87.120 & 0.714 & 0.323 & 45.907 & 47.492 & 6.602 \\
\hline 3 & 0.297 & 91.509 & 8.279 & 0.212 & 0.233 & 11.820 & 83.245 & 4.935 & 0.336 & 45.775 & 47.063 & 7.162 \\
\hline 4 & 0.310 & 87.524 & 12.267 & 0.209 & 0.233 & 11.794 & 82.617 & 5.589 & 0.349 & 45.275 & 47.210 & 7.515 \\
\hline 5 & 0.315 & 85.999 & 13.595 & 0.406 & 0.234 & 11.760 & 82.273 & 5.967 & 0.355 & 45.362 & 47.375 & 7.263 \\
\hline 6 & 0.318 & 85.198 & 14.250 & 0.552 & 0.234 & 11.827 & 82.213 & 5.960 & 0.357 & 45.335 & 47.410 & 7.255 \\
\hline 7 & 0.320 & 84.835 & 14.590 & 0.574 & 0.234 & 11.832 & 82.190 & 5.978 & 0.358 & 45.292 & 47.425 & 7.283 \\
\hline 8 & 0.320 & 84.673 & 14.738 & 0.589 & 0.234 & 11.831 & 82.184 & 5.985 & 0.358 & 45.294 & 47.442 & 7.264 \\
\hline
\end{tabular}




\begin{tabular}{|c|c|c|c|c|c|c|c|c|c|c|c|c|}
\hline 9 & 0.321 & 84.589 & 14.811 & 0.601 & 0.234 & 11.833 & 82.182 & 5.985 & 0.359 & 45.292 & 47.447 & 7.261 \\
\hline 10 & 0.321 & 84.549 & 14.847 & 0.605 & 0.234 & 11.833 & 82.181 & 5.985 & 0.359 & 45.289 & 47.449 & 7.262 \\
\hline \multirow{3}{*}{ Period } & \multicolumn{12}{|c|}{ Southwest China } \\
\hline & \multicolumn{4}{|c|}{ Variance decomposition of ML } & \multicolumn{4}{|c|}{ Variance decomposition of EC } & \multicolumn{4}{|c|}{ Variance decomposition of TC } \\
\hline & S.E. & ML & $\mathrm{EC}$ & $\mathrm{TC}$ & S.E. & ML & EC & $\mathrm{TC}$ & S.E. & ML & $\mathrm{EC}$ & $\mathrm{TC}$ \\
\hline 1 & 0.200 & 100.000 & 0.000 & 0.000 & 0.159 & 6.339 & 93.661 & 0.000 & 0.228 & 45.541 & 50.088 & 4.371 \\
\hline 2 & 0.243 & 86.167 & 4.278 & 9.555 & 0.159 & 6.299 & 93.688 & 0.013 & 0.288 & 45.690 & 40.510 & 13.800 \\
\hline 3 & 0.247 & 86.305 & 4.137 & 9.559 & 0.159 & 6.324 & 93.654 & 0.022 & 0.292 & 47.137 & 39.250 & 13.613 \\
\hline 4 & 0.248 & 86.206 & 4.137 & 9.657 & 0.159 & 6.329 & 93.647 & 0.024 & 0.294 & 47.333 & 38.976 & 13.690 \\
\hline 5 & 0.248 & 86.204 & 4.133 & 9.663 & 0.159 & 6.331 & 93.645 & 0.024 & 0.294 & 47.377 & 38.932 & 13.691 \\
\hline 6 & 0.248 & 86.202 & 4.133 & 9.665 & 0.159 & 6.331 & 93.645 & 0.024 & 0.294 & 47.384 & 38.924 & 13.692 \\
\hline 7 & 0.248 & 86.202 & 4.133 & 9.666 & 0.159 & 6.331 & 93.645 & 0.024 & 0.294 & 47.385 & 38.922 & 13.692 \\
\hline 8 & 0.248 & 86.202 & 4.133 & 9.666 & 0.159 & 6.331 & 93.645 & 0.024 & 0.294 & 47.386 & 38.922 & 13.692 \\
\hline 9 & 0.248 & 86.201 & 4.133 & 9.666 & 0.159 & 6.331 & 93.645 & 0.024 & 0.294 & 47.386 & 38.922 & 13.692 \\
\hline 10 & 0.248 & 86.201 & 4.133 & 9.666 & 0.159 & 6.331 & 93.645 & 0.024 & 0.294 & 47.386 & 38.922 & 13.692 \\
\hline \multirow{3}{*}{ Period } & \multicolumn{12}{|c|}{ Qinghai-Tibet region } \\
\hline & \multicolumn{4}{|c|}{ Variance decomposition of ML } & \multicolumn{4}{|c|}{ Variance decomposition of EC } & \multicolumn{4}{|c|}{ Variance decomposition of TC } \\
\hline & S.E. & ML & EC & $\mathrm{TC}$ & S.E. & ML & EC & $\mathrm{TC}$ & S.E. & ML & EC & $\mathrm{TC}$ \\
\hline 1 & 0.251 & 100.000 & 0.000 & 0.000 & 0.203 & 0.302 & 99.698 & 0.000 & 0.430 & 57.261 & 40.410 & 2.329 \\
\hline 2 & 0.271 & 86.528 & 13.420 & 0.052 & 0.209 & 1.026 & 94.813 & 4.162 & 0.445 & 55.414 & 40.303 & 4.283 \\
\hline 3 & 0.309 & 66.599 & 33.050 & 0.351 & 0.214 & 5.612 & 89.979 & 4.408 & 0.475 & 50.330 & 45.894 & 3.776 \\
\hline 4 & 0.314 & 65.241 & 33.072 & 1.687 & 0.216 & 5.928 & 89.439 & 4.633 & 0.480 & 50.261 & 44.971 & 4.768 \\
\hline 5 & 0.317 & 65.259 & 32.873 & 1.869 & 0.217 & 5.907 & 89.380 & 4.713 & 0.483 & 50.201 & 45.075 & 4.724 \\
\hline 6 & 0.318 & 65.259 & 32.697 & 2.044 & 0.217 & 5.913 & 89.363 & 4.724 & 0.484 & 50.198 & 44.959 & 4.843 \\
\hline 7 & 0.319 & 65.232 & 32.726 & 2.042 & 0.217 & 5.908 & 89.365 & 4.726 & 0.484 & 50.155 & 45.008 & 4.837 \\
\hline 8 & 0.319 & 65.228 & 32.723 & 2.049 & 0.217 & 5.910 & 89.354 & 4.736 & 0.484 & 50.151 & 44.998 & 4.851 \\
\hline 9 & 0.319 & 65.215 & 32.737 & 2.048 & 0.217 & 5.910 & 89.353 & 4.737 & 0.484 & 50.142 & 45.007 & 4.850 \\
\hline
\end{tabular}




\begin{tabular}{l|l|l|l|l|l|l|l|l|l|l|l|l}
\hline 10 & 0.319 & 65.213 & 32.736 & 2.051 & 0.217 & 5.910 & 89.352 & 4.738 & 0.484 & 50.141 & 45.006 & 4.853 \\
\hline
\end{tabular}

\section{Conclusion}

591 This study examines the regional differences in the dynamic efficiency of ACE from 2001 to 2017 in

592 China, and empirically analyzes the dynamic effects of the internal structure of dynamic efficiency by

593 using the Dagum Gini coefficient and the PVAR model. The results of this study found that: (i) the

594 overall dynamic efficiency of China's ACE is in a state of "efficiency optimization", but most provinces

595 in the Southwest and Huanghuaihai regions are in a state of "inefficiency"; numerically, the dynamic

596 efficiency was higher in 2017 than in 2001. Technological change and technological efficiency change

597 are in a state of "inefficiency" in most areas, and "regions of efficiency decline" present a clustering

598 phenomenon in the spatial structure of emissions in the region. In addition, in the early period of the

599 study (2001-2009), technological change was found to be the main factor leading to dynamic

600 efficiency change, while in the later period (2010-2017), technological efficiency change dominated

601 the dynamic efficiency. (ii) In terms of regional differences, the overall Dagum Gini coefficient of

602 China's ACE dynamic efficiency, technological change, and technological efficiency change all show

603 upward trends; this indicates that the domestic gap is gradually widening. Among the differences

604 within and between regions, the contribution of technological efficiency change and technological

605 change to the dynamic efficiency of China's ACE varies greatly between regions. In economically

606 developed regions, technological efficiency change drives dynamic efficiency, whereas technological

607 change is the main driver of dynamic efficiency in underdeveloped regions. In terms of the

608 performance of the contribution rate, we found that the gap between regions and the transvariation

609 intensity are the main reasons for the gap between dynamic efficiency, technological change, and

610 technological efficiency change in China's ACE. These two factors perform differently in different

611 samples and during different time periods. (iii) In the analysis of the internal formation of dynamic

612 efficiency, we found that the technological change, technological efficiency change, and dynamic

613 efficiency interacted with one another in terms of intensity, direction, and continuity.

\section{References}

616 Beinhocker E, Oppenheim J, Irons B, Lahti M, Farrell D, Nyquist S, Remes J, Naucler T, Enkvist P A

617 (2008) The Carbon Productivity Challenge: Curbing Climate Change and Sustaining Economic Growth.

618 Mc Kinsey Global Institute

619 Chen X-H, Yi G-D, Liu X (2017) Analysis of the Low Carbon Economy Efficiency in China: Based on

620 a Method of Three Stage SBM-DEA Model with Undesirable Outputs. Operations Research and

621 Management Science 26(03):115-122

622 Choi Y, Zhang N, Zhou P (2012) Efficiency and abatement costs of energy-related CO2 emissions in

623 China: A slacks-based efficiency measure. Appl Energy 98:198-208

624 Chung Y-H, Fare R, Grosskopf S (1997) Productivity and Undesirable Output: A Directional Distance 
626 Dagum C (1997) A new approach to the decomposition of the Gini income inequality ratio. Empirical

627 Economics 22(4):515-531

628 Dogan E, Sebri M, Turkekul B (2016) Exploring the relationship between agricultural electricity 629 consumption and output: New evidence from Turkish regional data. Energy Policy 95(08):370-377

630 Dong F, Long R, Bian Z, et al (2107) Applying a Ruggiero three-stage super-efficiency DEA model to 631 gauge regional carbon emission efficiency: evidence from China. Nat Hazards 87

632 Dong H-M, Li Y-E, Tao X-P, et al (2008) China greenhouse gas emissions from agricultural activities 633 and its mitigation strategy. Trans Chin Soc Agric Eng 24(10) : 269-273

634 Fei R, Lin B (2016) Technology gap and CO2 emission reduction potential by technical efficiency 635 measures: A meta-frontier modeling for the Chinese agricultural sector. Ecol Indic 73(02.):653-661

636 Fried H O, Lovell C A K, Schmidt S S, Yaisawarng S (2002) Accounting for Environmental Effects and 637 Statistical Noise in Data Envelopment Analysis. Journal of Productivity

638 FÄRE R, Grosskopf S, Noh D-W et al (2005) Characteristics of a polluting technology: theory and 639 practice. Journal of Econometrics 126(2):469-492

640 Färe R, Grosskopf S, Norris M, Zhang Z (1994) Productivity Growth, Technical Progress and Efficiency 641 Change in Industrialized Countries. American Economic Review 84 (1), 66-83

642 Guo S-D, Qian Y-B, Zhao R (2018) Analysis of Agricultural Carbon Emission Efficiency and 643 Convergence in Western China-Based on the SBM-Undesirable Model. Rural Economy (11):80-87

644 Gómez-Calvet R, Conesa D Gómez-Calvet A R, et al (2014) Energy efficiency in the European Union:

645 What can be learned from the joint application of directional distance functions and slacks-based 646 measures? Appl Energy 132:137-154

647 Han Y-F, Zhang L (2013) Research on Decomposition of Chinese Agricultural Carbon Emission Change 648 Factors-Based on the LMDI Decomposition Method from the Perspective of Energy Consumption and 649 Trade. Contemporary Economic Research (04):47-52

650 He Y-Q, Dai X-W (2016) Phase characteristics and regional differences in agriculture carbon emissions 651 in China. Resources Science 38(9) 1780-1790

652 Huang G-Q, Bai L-B (2019) Study on Industrial Energy Efficiency and Influencing Factors in Shaanxi

653 Province: Based on Three-Stage Super-Efficiency DEA Model. Ecological Economy 35(04):58-64

654 Iftikhar Y, He W, Wang Z (2016) Energy and CO2 emissions efficiency of major economies: A non655 parametric analysis. J Cleaner Prod 139:779-787

656 Ismael M, Srouji F, Boutabba MA (2018) Agricultural technologies and carbon emissions: evidence from 657 Jordanian economy. Environ Sci Pollut Res 1:10867-10877 
659 greenhouse gas emissions. Environ Pollut 150(6):107-124

660 Kortelainen M (2008) Dynamic Environmental Performance Analysis: A Malmquist Index Approach. 661 Ecological Economics 64(4),701-715

662 Lei Z-D, Chen Z-Z, Li W-M (2020) A Nonlinear Empirical Study of Agricultural Technology Progress 663 on Agricultural Carbon Emission Efficiency. Statistics \& Decision 36(05):67-71

664 Li G-Z, Li Z-Z (2010) An Empirical Analysis of the Decomposition of Carbon Emission Factors in

665 China's Agricultural Energy Consumption-Based on the LMDI Model. Journal of Agrotechnical 666 Economics (10):66-72

667 Li J-K, Ma J-J, Wei W (2020) Study on Regional Differences of Energy Carbon Emission Efficiency in 668 Eight Economic Area of China. The Journal of Quantitative \& Technical Economics 37(06):109-129

669 Liu L-N, Wang C-Y, et al (2019) Analysis of LMDI Decomposition and Decoupling Effects of Regional 670 Agricultural Carbon Emissions. Statistics \& Decision 35(23):95-99

671 Liu M-L, Zhu L, Fan Y (2011) Evaluation of Carbon Emission Performance and Estimation of Marginal 672 CO2 Abatement Costs for Provinces of China: A Non-parametric Distance Function Approach. China 673 Soft Science (03):106-114

674 Marklund P O, Samakovlis E (2007) What is driving the EU Burden-sharing Agreement: efficiency or equity? J Environ Manage 85(2):317-329

676 Molinos-Senante M, Sala-Garrido R, Hernández-Sancho F (2016) Development and application of the

677 Hicks-Moorsteen productivity index for the total factor productivity assessment of waste water

678 treatment plants. J Cleaner Prod 112:3116-3123

679 Peter, C, Helming, K, Nendel, C (2017) Do greenhouse gas emission calculations from energy crop 680 cultivation reflect actual agricultural management practices?-A review of carbon footprint calculators.

681 Renewable Sustainable Energy Rev 67, 461-476

682 Shan H-J (2008) Re-estimating the Capital Stock of China:1952-2006. The Journal of Quantitative \& 683 Technical Economics 25(10):17-31

684 Song M, An Q, Zhang W et al (2012) Environmental efficiency evaluation based on data envelopment

685 analysis: A review. Renewable Sustainable Energy Rev 16(7):4465-4469

686 Song Z-L, Liao Z-D (2014) Estimates of Fixed Capital Stock by Sector and Region: 1978—2011. Journal 687 of Guizhou University of Finance and Economics (03):8-16

688 Tian Y, Zhang J-B (2017) Dynamic evolution and convergence on the development of China's low carbon 689 agriculture. Journal of Arid Land Resources and Environment 31(03):1-7

690 Tone K (2001) A slacks-based measure of efficiency in data envelopment analysis. European Journal of 691 Operational Research 130(3):498-509 

and greenhouse gas emissions: trade-offs or synergies between mitigation and food security? Environ Res Lett 8(3), DOI: 10.1088/1748-9326/8/3/035019

Wang H-F (2020) Temporal and Spatial Analysis of County Agricultural Efficiency in Anhui Province and Dynamic Perspectives. Energy 74,322-330

699 West T O, Marland G A (2002) Synthesis of carbon sequestration, carbon emissions, and net carbon flux in agriculture: comparing tilage practices in the United States. Agricultural, Ecosystems and Environment 91(1):217-232

702 Wu J, Tan T, et al (2019) China's Total Factor Energy Efficiency Evaluation-Based on Non-separable Three-Stage DEA Model. Journal of Applied Statistic and Management 38(03):418-432

704 Xia S-Y, Zhao Y, Xu X, et al (2020) Regional Inequality, Spatial-Temporal Pattern and Dynamic 705 Evolution of Carbon Emission Intensity from Agriculture in China in the Period of 1997 - 2016. Resour Environ Yangtze Basin 29(03):596-608

707 Xu G-Q, Luan H (2018) Spatial Difference and Influencing Factors of Carbon Dioxide Emission 708 Efficiency in Jiangsu: Analysis Based on Improved Three Stage SBM-DEA Model. Ecological Economy 709 34(07):33-38

710 Xu X-X, Zhou J-M, Shu Y (2007) Estimates of Fixed Capital Stock by Sector and Region:1978 - 2002.

711 Statistical Research (05):6-13

712 Zhang J, Wu G-Y, Zhang J-P (2004) The Estimation of China' s provincial capital stock:1952 —2000.

713 Economic Research Journal (10):35-44

714 Zhou P, Ang B-W, Han J-Y (2010) Total factor carbon emission performance: A Malmquist index 715 analysis. Energy Economics 32(1):194-201

716 Zhou W-Q, Nie M (2012) Regional differences in the efficiency of Industry carbon emissions in China.

717 The Journal of Quantitative \& Technical Economics 29(09):58-70+161. Analysis,17(1/2),157 174

\section{Author information}

$720 \quad$ Affiliations

721 Xiaodan Zhang, Kaicheng Liang, Xianghong Zhou

722 School of Economics and Management, Tongji University, Shanghai, China, 200092

\section{Corresponding author}


726 School of Economics and Management, Tongji University, Shanghai, China, 200092

727 xhztongji0927@163.com

Ethics declarations

Ethical approval

731 Not applicable.

\section{Consent to Participate}

734 Not applicable.

\section{Consent to publication}

737 Not applicable.

Availability of data and materials

740 The datasets used and/or analysed during the current study are available from the corresponding author 741 on reasonable request.

\section{Competing interests}

744 The authors declare that they have no competing interests.

Fund

747 This research was supported by the China Academic Degrees \& Graduate Education Development 748 Center (ZT20201030)

\section{Contributions}

751 Conceptualization: Xiaodan Zhang, Kaicheng Liang, and Xianghong Zhou. Methodology: Xiaodan

752 Zhang, Kaicheng Liang. Formal analysis and investigation: Xiaodan Zhang, Kaicheng Liang, Xianghong 753 Zhou. Writing-original draft preparation: Xiaodan Zhang, Kaicheng Liang, Xianghong Zhou. Writing754 review and editing: Xiaodan Zhang, Kaicheng Liang. Funding acquisition: Xianghong Zhou. Resources: 
755

Xiaodan Zhang, Kaicheng Liang, Xianghong Zhou. Supervision: Xiangdan Zhang.

756

757 